\title{
As práticas informacionais dos profissionais de software em seus contextos culturais: uma abordagem fenomenológica e hermenêutica
}

\begin{abstract}
Leonardo Pereira Pinheiro de Souza Universidade Estadual Paulista, Faculdade de Filosofia e Ciências, Departamento de Ciência da Informação, Marília, SP, Brasil leopinheirodesouza@gmail.com

Cassia Regina Bassan de Moraes Universidade Estadual Paulista, Faculdade de Filosofia e Ciências, Departamento de Ciência da Informação, Marília, SP, Brasil crbassan@gmail.com

Marta Lígia Pomim Valentim Universidade Estadual Paulista, Faculdade de Filosofia e Ciências, Departamento de Ciência da Informação, Marília, SP, Brasil valentim@valentim.pro.br
\end{abstract}

DOI: https://doi.org/10.26512/rici.v13.n3.23872

Resumo: Verifica-se que os desenvolvedores de softwares utilizam informação e conhecimento para programação e alteração de códigos-fonte de programas. Compreende-se que os modos coletivos de lidar com a informação, a cultura informacional, estão imbrincados na cultura organizacional. Evidencia-se que a cultura organizacional é peculiar a cada empresa, mas influenciada por perspectivas partilhadas na cultura profissional. Denota-se que as práticas informacionais, tema emergente nos estudos de usuários, evidenciam fatores subjetivos e coletivos na relação com a informação e o conhecimento. Objetiva-se investigar as práticas informacionais dos desenvolvedores de software na intersecção das culturas profissional, organizacional e informacional, verificando valores informacionais coletivos, implícitos nos discursos individuais. Busca-se identificar valores informacionais comuns entre empresas de software, representando a cultura profissional, e valores peculiares às culturas organizacionais. Objetiva-se ainda identificar aspectos positivos e a melhorar nas práticas informacionais. Utilizase como procedimentos metodológicos o estudo de casos múltiplos, mediante entrevistas com gestores e programadores de duas empresas. Emprega-se a análise de conteúdo categorial e a fenomenologia hermenêutica de Paul Ricoeur para análise e interpretação dos dados, elucidando aspectos coletivos subjacentes no discurso individual. Apresenta-se como resultados que os elementos culturais em comum nas organizações enfatizam a socialização informal de informações e conhecimentos, havendo dificuldade em documentá-los, primazia da Internet como fonte informacional, e outros aspectos. Conclui-se que as práticas informacionais surgem

\footnotetext{
${ }^{1}$ O presente trabalho foi realizado com apoio da Coordenação de Aperfeiçoamento de Pessoal de Nível superior - Brasil (CAPES) - Código de financiamento 001.
} 
na confluência de múltiplos fatores culturais com o fazer profissional e que, sendo construídas na experiência empírica do trabalho, necessitam ser refletidas mediante a Ciência da Informação, corrigindo lacunas e as aprimorando, para atingir os objetivos organizacionais.

Palavras-Chave: Estudos de usuários. Fenomenologia. Hermenêutica. Programação. Cultura organizacional.

The information practices of software professionals in their cultural contexts: a phenomenological and hermeneutic approach

Abstract: It is verified that software developers use information and knowledge for programming and modification of program's source codes. It is understood that the collective ways of dealing with information, informational culture, are intertwined in organizational culture. It is evident that organizational cultures are peculiar to each company but influenced by shared perspectives in a professional culture. It is noted that informational practices, an emerging theme in user studies, show subjective and collective factors in the subjects' relationship with information and knowledge. It is aimed, therefore, to investigate the informational practices of software developers at the intersection of professional, organizational and informational cultures, verifying collective informational values, implicit in individual discourses. It is intended to identify informational values common among software companies, representing professional culture, and values peculiar to organizational cultures. It also aimed to identify positive and factors to improve in informational practices. Multiple case studies are used as methodological procedures, through interviews with managers and programmers from two companies. The categorical content analysis and Paul Ricoeur's hermeneutic phenomenology is used to analyze and interpret data, elucidating collective aspects underlying individual discourses. The results show that common cultural elements in organizations emphasize informal socialization of information and knowledge, with difficulties in documenting them, primacy of the Internet as an informational source, and other aspects. It is concluded that informational practices arise at the confluence of multiple cultural factors with professional practice and that, being built on work's empirical experience, they need to be reflected through contributions from Information Science, correcting gaps and improving them, to achieve organizational objectives.

Keywords: User studies. Phenomenology. Hermeneutics. Programming. Organizational culture.

Las prácticas informacionales de los profesionales de software en sus contextos culturales: un enfoque fenomenológico y hermenéutico

Resumen: Se verifica que los desarrolladores de software usan información y conocimiento para la programación y alteración de códigos fuente de programas. Se entiende que las formas colectivas de tratar la información, la cultura informacional, están entrelazadas en la cultura organizacional. Se evidencia que la cultura organizacional es peculiar de cada empresa, pero influenciada por perspectivas compartidas en la cultura profesional. Se verifica que las prácticas informacionales, tema emergente en estudios de usuarios, muestran factores subjetivos y colectivos en la relación de los sujetos con la información y el conocimiento. Se objetiva investigar las prácticas informacionales de los desarrolladores de software en la intersección de las culturas profesional, organizacional e informacional, verificándose valores informacionales colectivos, implícitos en los discursos individuales. Se busca identificar valores informacionales comunes entre las compañías de software, en la cultura profesional, y valores propios de las culturas organizacionales. Se tiene también como objetivo identificar aspectos positivos y por mejorar en las prácticas informacionales. Se utiliza el estudio casos múltiples como procedimientos metodológicos, efectuando entrevistas con gerentes y programadores de dos compañías. Se utiliza el análisis de contenido categorial y la fenomenología hermenéutica de Paul Ricoeur analizando e interpretando datos, aclarando los aspectos colectivos que subyacen 
al discurso individual. Se muestran en los resultados elementos culturales en común en las organizaciones, enfatizando la socialización informal de la información y conocimiento, con dificultades para documentarlos, primacía de Internet como fuente de información y otros aspectos. Se concluye que las prácticas informacionales surgen en la confluencia de múltiples factores culturales con la práctica profesional y que, basándose en la experiencia empírica del trabajo, deben reflexionarse por medio de la Ciencia de la Información, corrigiendo brechas y perfeccionándolas, para lograr los objetivos organizacionales.

Palabras clave: Estudios de usuarios. Fenomenología. Hermenéutica. Programación. Cultura organizacional.

\section{Introdução}

O contexto contemporâneo é cada vez mais dependente da tecnologia para a transmissão, processamento e armazenamento de informações. No campo empresarial, a simbiose com as Tecnologias de Informação e Comunicação (TIC) mostra-se evidente, tanto para execução e controle de processos rotineiros quanto para a competitividade e inovação. Nessa perspectiva, "[...] entender o contexto do desenvolvimento de software e encontrar maneiras de aprimorá-lo não é bom apenas para empresas de tecnologia, mas para [...] empresas de qualquer setor" (BALLE et al., 2018, p. 381, tradução nossa).

Informação e conhecimento são elementos centrais na atividade de programação, enfocada no presente trabalho, referindo-se à criação, alteração, correção de código de software e questões correlatas. Peters e Pedrycz (2001) afirmam que descobrir como o conhecimento e a informação são adquiridos e utilizados ajuda a aprimorar o processo de desenvolvimento de software, concernente à qualidade dos produtos, ao desempenho de seus desenvolvedores, à organização e eficiência das equipes. Esse é um trabalho essencialmente intelectual e complexo, que tem a informação e o conhecimento como suas principais 'matériasprimas'. Deste modo, é relevante entender como os profissionais já referidos utilizam recursos informacionais para executar seu trabalho, suas práticas informacionais, analisando os pontos fortes e aspectos a melhorar. No presente artigo, denominam-se desenvolvedores de software os que se dedicam à programação e atividades afins.

Para Araújo (2017), as práticas informacionais são uma abordagem emergente de estudos de usuários que busca conciliar as disposições sociais coletivamente construídas, culturais, valorativas e afins, com as perspectivas individuais e subjetivas, na relação das pessoas com a informação e o conhecimento. Busca-se investigar a convergência entre o coletivo e o individual no aspecto informacional, sem negar a validade de nenhuma dessas perspectivas.

Peters e Pedrycz (2001) afirmam que a boa gestão de equipes de desenvolvimento de software depende da compreensão de padrões comportamentais individuais e coletivos, que são influenciados pela cultura organizacional. Essa cultura é um "[...] conjunto de crenças, 
suposições, valores, normas, artefatos, símbolos, ações e padrões de linguagem compartilhados por todos os membros de uma organização" (HUFF, 2014, online, tradução nossa). Ou ainda, complementando, "[...] o conjunto de valores compartilhados [...] que ajudam as pessoas dessa organização a compreender quais atitudes são consideradas adequadas e quais são inaceitáveis" (GRIFFIN; MOORHEAD, 2006, p. 399-400, tradução nossa). As posturas quanto à informação e ao conhecimento nas empresas estão também sujeitas às influências da cultura organizacional, configurando a cultura informacional (VALENTIM, 2014; MORAES; BARBOSA, 2015). Para Valentim (2014) a cultura informacional refere-se às normas, crenças, mitos, ritos e valores socialmente partilhados, concernentes à relação dos sujeitos com a informação, o conhecimento e os dados, alicerçada na estrutura organizacional, nos ambientes e nos fluxos informacionais formais e informais. Apesar de ser considerada um atributo único de cada empresa, a cultura organizacional é influenciada por valores amplamente compartilhados por indivíduos de uma mesma profissão, em um determinado contexto mercadológico (HOLLIFIELD; KOSICKI; BECKER, 2010; ABRAMOV, 2017; SCHEIN, 2007). Para Abramov (2017), a cultura profissional é um conjunto de conhecimentos, habilidades, esquemas conceituais, valores, convicções e regras partilhados em uma comunidade profissional, por meio da socialização, do trabalho e da educação.

Portanto considera-se, no presente artigo, a relação dos desenvolvedores de software com a informação na intersecção dos três contextos culturais: o profissional, o organizacional e o informacional.

Para Karahanna, Evaristo e Strite (2005), as culturas profissional e organizacional são baseadas nas práticas laborais, sendo que estas influenciam a criação de seus valores. No desenvolvimento de software, essas práticas se referem ao projeto, programação, manutenção e evolução de sistemas computacionais. Ademais, Valentim (2013) explica que a relação dos sujeitos com a informação toma formas particulares de acordo com as especificidades de suas ocupações, bem como normas e costumes das organizações em que estão inseridos. "[...] o tipo de informação que necessitam é relacionado às responsabilidades, funções, atividades e tarefas desempenhadas" (Op. cit. p. 2019, 220). Neste sentido, o conceito de práticas informacionais traz uma perspectiva sociocultural, contemplando todo o espectro de ações do sujeito concernentes à informação, voltadas às práticas sociais e ao trabalho (DUARTE, ARAÚJO, PAULA, 2017).

Assim, apresentam-se os seguintes problemas: quais são as características da cultura profissional dos desenvolvedores de software que determinam sua relação com a informação? De que maneira as culturas organizacional e informacional interagem com a cultura profissional? Quais aspectos das práticas informacionais dos referidos profissionais são adequados à 
execução do trabalho e quais problemas podem ser identificados? Para responder a esses questionamentos, adotou-se uma perspectiva inspirada na Fenomenologia ${ }^{2}$ de Paul Ricoeur ${ }^{3}$, que busca elucidar valores institucionais coletivos por meio do discurso, como expressão da consciência individual, visando atingir os significados reais por trás do que está aparente (BLANCO-ILARI, 2005; BUDD, 2005; TERRA et al., 2009).

Portanto, objetiva-se investigar as práticas informacionais dos desenvolvedores de software no contexto das culturas profissional, organizacional e informacional, verificando valores coletivos concernentes à informação e ao conhecimento, implícitos nos discursos individuais, por meio de uma abordagem fenomenológica e hermenêutica. Busca-se identificar categorias de valores culturais sobre a informação e o conhecimento em comum entre empresas de software, que possam representar indícios de uma cultura profissional, bem como valores distintos, evidenciando traços peculiares às suas culturas organizacionais. Por fim, objetiva-se ainda identificar aspectos positivos e aspectos que necessitem melhorias quanto às práticas informacionais.

\section{Fundamentação teórica}

O presente trabalho trata da relação dos desenvolvedores de software com a informação e o conhecimento a partir de uma perspectiva que integra os fatores individuais e contextuais, enfocando o aspecto cultural. Essa perspectiva delimita-se no que Capurro (2007) define como paradigma social da Ciência da Informação $(\mathrm{Cl})$, que enfatiza os fatores sociais, culturais e históricos, em contraposição à perspectiva anterior puramente cognitivista. Assim, adota-se no presente trabalho um conceito de informação que se coaduna com a visão acima exposta, o denominado 'sentido ainda mais amplo', elaborado por Saracevic (1999), que não trata a informação apenas como sinais e mensagens objetificados, nem como fenômeno puramente cognitivo e individual, mas como sendo também um construto contextual/social:

[...] a informação envolve não apenas mensagens (primeiro sentido) que são processadas cognitivamente (segundo sentido), mas também um contexto situação, tarefa, problema em questão e afins [...]. Além de outros sentidos, envolve motivação ou intencionalidade e, portanto, está conectado ao

\footnotetext{
${ }^{2}$.A fenomenologia é um movimento filosófico cujo cerne é a investigação de fenômenos vivenciados na consciência, buscando apreendê-los o mais livre possível de pressuposições e preconceitos, tendo como seu grande expoente o filósofo alemão Edmund Husserl (1859-1938), a partir do qual derivaram distintas correntes de pensamento, muitas tendo pouco em comum além dessa origem partilhada (BIEMEL; SPIEGELBERG, 2008).

${ }^{3}$ Jean Paul Gustave Ricoeur (1913-2005) foi um filósofo e historiador francês, estudioso de teorias psicanalíticas e linguísticas da interpretação (PAUL RICOEUR, 2005). Seu trabalho buscou uma mediação entre a fenomenologia e as interpretações aparentemente conflitantes de movimentos como o estruturalismo, pós-estruturalismo, hermenêutica e semiótica (Ibid.).
} 
contexto ou horizonte social expansivo, como cultura, trabalho ou problema em questão (Op. cit., p. 1054, tradução nossa).

É importante também conceituar o conhecimento. Para Terret (1998), conhecimento é um corpus de informação carregado de significado e insight, mesclado com um amálgama de saberes e experiências pessoais prévios. Segundo Almeida Júnior (2015), a criação do conhecimento pessoal é um processo social, intersubjetivo, mediado pelas perspectivas e experiências de vários outros indivíduos, que são apropriadas pelo ser cognoscente. É fato que cada indivíduo possui a própria personalidade e, portanto, estabelece o próprio modo de se relacionar com a informação. É também fato que os valores presentes nos meios sociais são influenciadores da relação do indivíduo com a informação.

Duarte, Araújo e Paula (2017) apresentam o conceito de práticas informacionais, ressaltando que este possibilita analisar o modo como o contexto social interfere na relação do sujeito com a informação e, também, as peculiaridades do indivíduo, o modo como ele é capaz de interferir nesse contexto. A análise das práticas informacionais revela a complexidade dos processos informacionais, demonstrando a interação dialética entre indivíduo e coletivo, que ao mesmo tempo se opõem, se harmonizam e se modificam mutuamente. Para Araújo (2017), as práticas informacionais buscam capturar os valores socialmente partilhados sobre o que é informativo, as características das necessidades de informação, as fontes de informação consideradas relevantes, bem como as concepções individuais sobre aceitação ou não desses valores, e o modo como são internalizados.

Esse campo de estudo aparentemente peculiar encontra amparo na Fenomenologia. Para Terto e Duarte (2014), a Fenomenologia aproxima-se da Psicologia, tendo como objeto a descrição do fenômeno vivenciado pelo indivíduo, elucidando a percepção da experiência por meio da análise da consciência. A tônica social da Fenomenologia é evidenciada na obra de Paul Ricoeur.

Budd (2005) explica que Ricoeur enfatiza o papel da interpretação na compreensão da consciência, baseada na hermenêutica ${ }^{4}$, por meio da expressão da linguagem e do discurso. Blanco-Ilari (2005) destaca que, na concepção de Ricoeur, o discurso é a tradução linguística da percepção, visto que se refere a algo já mencionado anteriormente por outros, construindo a trama de inter-relações humanas e relações entre as instituições. Ou seja, as palavras de um

\footnotetext{
${ }^{4}$ A Hermenêutica como uma metodologia da interpretação procura discernir os significados das ações humanas, textos e elementos correlatos, a partir de um instrumental baseado em evidências empíricas sólidas, auxiliando a lidar com problemas de disciplinas como Jurisprudência, Teologia, Literatura e outras (MANTZAVINOS, 2016). Firmou-se na Filosofia por meio do trabalho de Friedrich Schleiermacher, no início do século XIX (Ibid.).
} 
indivíduo frequentemente remetem a ideias e valores comuns em seus círculos de convivência, perpetuando-os por meio de seu discurso, quer esse indivíduo se dê conta disso ou não.

O conceito de instituição aqui é compreendido de maneira ampla, não se referindo especificamente a instituições políticas, educacionais ou empresariais concretas. De acordo com Blanco-Ilari (2005), instituição, na concepção de Ricoeur, representa as normas e valores que possibilitam a vida em sociedade, que, por sua vez, dão coesão às diversas coletividades humanas. $O$ trabalho de Ricoeur enfatiza a hermenêutica, por meio da qual se interpretam os valores institucionais.

Para Terra et al. (2009), Hermenêutica é um sistema de interpretação que traz à luz significados subjacentes em um texto, desvelando símbolos sociais por meio do registro da fala, do gesto e do sentimento, revelando o que está oculto no sentido aparente. Ressalta-se que os valores coletivos estão impregnados no discurso do sujeito, mesclados com aspectos da própria subjetividade, orientando a ação desse sujeito.

Budd (2005) enfatiza a importância de Ricoeur no âmbito da $\mathrm{Cl}$, visto que, ao contextualizar o sujeito na instituição, se quebra o caráter dialógico estrito do discurso, denotado na relação emissor-receptor, ampliando-se essa visão para contemplar aspectos sociais imbuídos na estrutura das bibliotecas, na construção dos tesauros, dos sistemas de informação e outras aplicações. No âmbito empresarial, os valores e normas coletivos apresentam-se em três principais esferas: a cultura profissional, a cultura organizacional e a cultura informacional, cujo assunto será abordado na próxima subseção.

\subsection{Fatores Culturais}

Inicialmente, é pertinente discutir sobre a cultura profissional, pois ela possui considerável influência sobre a formação da cultura organizacional e, em consequência, afeta também os modos pelos quais os sujeitos organizacionais interagem com a informação e o conhecimento.

A cultura profissional varia de acordo com o nível de abstração de conhecimento requerido para a prática profissional, nível educacional dos praticantes, orientação para a ciência e academia, prestígio e poder do grupo que a detém, sendo perpetuada por meio de símbolos, rituais e uma retórica própria, que sustentam sua legitimidade e reconhecimento perante a sociedade (SIEGRIST, 2015). Segundo Abramov (2017), essa cultura é importante para a construção da identidade coletiva, provendo um sistema de interpretação da realidade laboral, que serve para lidar com situações rotineiras e também inesperadas. Essa cultura é influenciada fortemente por fatores mercadológicos. 
Hollifield, Kosicki e Becker (2010) discorrem que organizações que atuam em um mesmo nicho de mercado criam uma cultura comum, partilhando tecnologias similares, processos de trabalho e valores sobre produção. Embora haja um núcleo cultural comum, cada organização desenvolve uma visão própria sobre como seus membros devem realizar o trabalho e tomar decisões, construindo uma cultura organizacional própria.

Para Schein (2007), a cultura organizacional orienta o comportamento dos sujeitos, por meio de normas e valores que são em parte vivenciados inconscientemente e não podem ser apreendidos em uma observação superficial. O autor afirma que a cultura organizacional é avaliada mediante a análise de três camadas: a superficial, dos artefatos, que são os comportamentos, linguagens, vestimentas, configurações arquitetônicas e afins, que podem ser observados; a intermediária, dos valores conscientemente defendidos pela organização; a profunda, dos valores que não são explicitamente comunicados, mas guiam as ações na organização, estando em acordo ou em conflito com os valores explícitos. Evidencia-se, assim, que há valores formalmente comunicados, visando formar uma visão positiva acerca da organização, tanto internamente quanto externamente. Há também valores que possivelmente não tenham sido considerados explicitamente como tais, mas se revelam nos hábitos sedimentados pelo tempo e no modo de pensar dos sujeitos organizacionais. Enquanto os valores explícitos podem ser artificialmente criados, outros valores, inferidos nas reais práticas e discursos dos sujeitos, podem ser considerados mais autênticos.

A cultura organizacional é onipresente na vida laboral, influenciando todos os seus aspectos, inclusive como os colaboradores se relacionam com a informação e o conhecimento, no âmbito da cultura informacional. Para Woida e Valentim (2006, p. 40), a cultura informacional é compreendida como um "[...] conjunto de pressupostos básicos composto por princípios, valores, crenças, ritos, e comportamentos positivos em relação à construção, socialização, compartilhamento e uso de dado, informação e conhecimento no âmbito corporativo".

Na mesma perspectiva, Moraes e Barbosa (2015) também entendem que a cultura informacional representa uma gama de comportamentos coletivamente construídos, que determinam o sentido e os usos da informação em si, dos padrões comunicacionais e da Tecnologia da Informação (TI) no âmbito da organização. Essa cultura é influenciada não só por variáveis internas da organização, mas também pelo mundo exterior. Para Hansen e Widén (2017, p. 555, tradução nossa), ela está “[...] baseada em um grande número de variáveis, como missão, história, liderança, características dos funcionários, ramo de atividade e cultura nacional".

Tendo sido discutida a conceituação de cultura informacional, é pertinente discorrer sobre as características culturais adequadas para atingir os objetivos organizacionais. Marchand, 
Kettinger e Rollins (2001) criaram uma métrica voltada ao uso eficaz da informação, visando à melhoria do desempenho organizacional, a chamada orientação informacional, que consiste em: emprego eficaz dos recursos de TIC; gestão eficaz da informação; desenvolvimento de comportamentos e valores informacionais adequados. Embora a cultura informacional não se resuma apenas aos valores informacionais, e facilmente se possa confundir os dois conceitos como sinônimos, esses valores são componentes fundamentais e relevantes evidências da essência da cultura, como já discutido (Seção 1).

Moraes e Barbosa (2015) enxergam nesses comportamentos e valores, definidos por Marchand, Kettinger e Rollins (2001), a caracterização de uma cultura informacional voltada para a excelência do desempenho organizacional, que "[...] consiste na capacidade de uma organização de estimular e capacitar para uma utilização eficaz da informação" (MORAES; BARBOSA, 2015, p. 135). Esses valores da 'cultura informacional modelo' constituem-se de: integridade ou normas éticas na relação com a informação; formalização ou uso de informação formalizada e registrada; controle ou uso de informações sobre produtividade para incentivar o bom desempenho dos colaboradores; transparência ou uso construtivo dos erros cometidos, propiciando correções e fomentando a aprendizagem organizacional; compartilhamento da informação; proatividade no uso da informação para executar o trabalho, tomar decisões e inovar (MARCHAND; KETTINGER; ROLLINS, 2001).

É natural do ser humano tentar reter para si qualquer coisa que represente ser vantajosa. Por isso, compartilhar nem sempre é fácil. Davenport e Prusak (1998) destacam como fatores inibidores para o compartilhamento de informação: falta de confiança; enxergar na informação uma ferramenta para obtenção de vantagens pessoais; falta de tempo.

Marchand, Kettinger e Rollins (2001) afirmam que a confiança, a unicidade de propósito e a cultura organizacional favorável são fatores impulsionadores desse compartilhamento. Conforme Koriat e Gelbard (2018), o desenvolvimento de software exige um compartilhamento constante de conhecimentos, porquanto há necessidade de se trabalhar em equipe.

Embora Marchand, Kettinger e Rollins (2001) afirmem que o controle informacional seja suficiente para que os sujeitos se conscientizem e enveredem pelo caminho das práticas informacionais eficazes, defende-se que trabalhar a motivação dos colaboradores seja a estratégia mais adequada. A motivação é definida como um impulso que dá propósito e direção ao comportamento por meio de alguns aspectos: “[...] (a) motivos fisiológicos [...], como fome, sede e necessidade de sono; (b) motivos pessoais, sociais ou secundários, como afiliação, competição e interesses e metas individuais (AMERICAN PSYCHOLOGICAL ASSOCIATION, 2018, online, tradução nossa). Compreende-se a motivação como um elemento impulsionador do comportamento, voltado à satisfação de uma necessidade física, psicológica e/ou social. 
De acordo com Stenius et al. (2016), a motivação é importante para os trabalhadores do conhecimento, pois destes se requer, principalmente, qualidade em recursos cognitivos ao invés de apenas quantidade. Nesse contexto, é fundamental que os gestores estabeleçam práticas informacionais positivas e efetivas, propiciando os incentivos que estiverem ao alcance de sua realidade organizacional, para que essas práticas sejam aceitas e efetivamente vivenciadas pelos colaboradores.

É relevante, portanto, destacar o nexo existente entre as práticas profissionais, as culturas organizacional e profissional, bem como a CI. Para Karahanna, Evaristo e Strite (2005), a cultura no âmbito do trabalho é formada e influenciada por camadas inter-relacionadas, que carregam valores e práticas: a camada supranacional, referente a aspectos religiosos, étnicos e afins; a nacional, referente aos costumes de cada país/região; a profissional e a organizacional, já descritas no presente trabalho. Para estes autores (2005), as camadas superiores da cultura, como a supranacional e a nacional, são compostas de valores inculcados desde a infância; as camadas de ordem inferior, as culturas profissional e a organizacional, possuem valores que não são tão profundamente assimilados na personalidade do sujeito, sendo essas culturas mais fortemente baseadas nas práticas, na experiência empírica do trabalho. Nas camadas superiores, os valores guiam as ações, e nas inferiores, as ações é que influenciam a criação dos valores.

Por exemplo, a cultura profissional implica a aquisição de ambos, valores e práticas, enquanto a cultura organizacional é composta primariamente de percepções compartilhadas de práticas organizacionais e, em menor extensão, de valores [...]. Valores são mais importantes que práticas nas culturas de nível mais elevado (exemplo, supranacional), e práticas e normas são dominantes para as culturas de nível mais baixo $(O p$. cit., p. 7, tradução nossa).

Pode-se inferir que, no desenvolvimento de software, essas práticas giram em torno das atividades de projeto, programação, manutenção e evolução de sistemas computacionais, sendo que seus valores profissionais, visão de mundo, derivam justamente dessas práticas laborais.

Valentim (2014) destaca a existência de subculturas na organização, referentes aos distintos departamentos e funções, mediante perspectivas geradas pelas suas respectivas culturas profissionais, o que evidencia a existência de peculiaridades em relação aos tipos de informações requeridas para o trabalho, usos e necessidades informacionais. "[...] o tipo de informação que necessitam é relacionado às responsabilidades, funções, atividades e tarefas desempenhadas" (VALENTIM, 2013, p. 219, 220). Assim, é destacado o papel central da prática profissional, condicionada por uma cultura profissional específica, que determina as 
particularidades das práticas informacionais. Como já exposto anteriormente (Seção 1), as práticas informacionais representam uma visão sociocultural da relação do sujeito com a informação, enfocando a relação dialógica entre esse sujeito e seu contexto, contemplando todo o espectro de ações concernentes à informação voltadas às práticas sociais e ao trabalho (DUARTE, ARAÚJO, PAULA, 2017).

\subsection{Desenvolvimento de Software, Cultura Profissional e Cultura Informacional}

Mediante o exame da literatura científica pode-se apreender alguns aspectos comuns na relação dos desenvolvedores de software com a informação que, por sua vez, também se revelam aspectos de sua cultura profissional, quais sejam: relevância da rede Internet como fonte de informação; relativa resistência à formalização da informação, com preferência pelos fluxos informacionais informais; sobrecarga de trabalho, que pode interferir no compartilhamento de informações, como afirmado por Davenport e Prusak (1998).

Sommerville (2007) afirma que, até meados da década de 1990, o desenvolvimento de software seguia metodologias pouco flexíveis às necessidades de alterações de projeto, pois requeriam a elaboração de meticulosa documentação, tornando-se inadequadas para acompanhar o acelerado contexto empresarial. Essa documentação refere-se a comentários escritos no código-fonte do software, diagramas e outros registros que descrevem a estrutura e configurações internas da aplicação. Os registros mencionados são divididos em dois grupos: “[...] uma parte deve dizer aos usuários e clientes, em linguagem natural, o que o sistema fará; uma segunda parte utiliza a terminologia técnica para descrever a estrutura, os dados e as funções do sistema" (PFLEEGER, 2004, p. 203).

Segundo Zhi et al. (2015), a documentação de software constitui-se de: descrição de requisitos de funcionamento do sistema; aspectos relativos ao projeto; comentários escritos no código-fonte explicitando seu funcionamento interno; casos de testes e afins. Conforme Zhi et al. (2015), a documentação deve prover informação precisa sobre o sistema desenvolvido e servir de instrumento de comunicação entre os membros de uma equipe de desenvolvimento.

No final da década de 1990, percebeu-se a necessidade de imprimir rapidez e desburocratizar os projetos de software. Segundo Sommerville (2007), desenvolveram-se então as metodologias ágeis, que diminuíram drasticamente a documentação em favor do enfoque na elaboração do software em si, com ampla participação do cliente nos processos de elaboração. Zhi et al. (2015, p. 176, tradução nossa) ressaltam que "[...] a visão tradicional de documentação de software está passando pelo desafio dos métodos de desenvolvimento ágil [...]". É importante frisar que as metodologias ágeis se tornaram um padrão consolidado para softwares empresariais, sendo que o uso de metodologias mais antigas, baseadas em um planejamento 
estrito das etapas do projeto e documentação meticulosa, se restringem mais à elaboração de softwares críticos, que requerem altíssimo nível de confiabilidade, como sistemas de controle de voo, bancários e afins (SOMMERVILLE, 2007; ZHI et al., 2015).

Diante de um enfoque produtivista e do risco de isto resultar em projetos com documentação insuficiente, existe a necessidade de incrementar a elaboração dessa documentação, auxiliando a compreensão do funcionamento interno do software, a comunicação entre a equipe de desenvolvimento e manutenção futura.

Balle et al. (2018) frisam a necessidade de melhorar o aspecto da explicitação ou registro de conhecimentos no âmbito nas metodologias ágeis, pois estas se baseiam preponderantemente no compartilhamento de conhecimento tácito e fluxos informacionais informais: "[...] métodos ágeis poderiam se beneficiar de uma documentação mais estruturada, como os modelos e esquemas usados [no método] cascata" (Op. cit., p. 388, tradução nossa). A chave para o sucesso no desenvolvimento de software refere-se a uma postura equilibrada sobre a documentação, investindo-se em qualidade e não puramente em volume.

Para Zhi et al. (2015), os atributos de qualidade para essa documentação são: acessibilidade; acuracidade; completude; consistência; correção; organização; legibilidade; concordância com as normas gramaticais; confiabilidade; rastreabilidade; atualização. A rastreabilidade, conforme os mesmos autores, está relacionada à atualização, à possibilidade de identificar as alterações feitas no documento ao longo do tempo, porque foram feitas e quem as fez.

Outro aspecto evidenciado na literatura é que, embora desenvolvedores de software utilizem menos documentação, a Internet é uma de suas fontes de informação mais utilizada. Especialmente populares são os fóruns ao estilo de redes sociais, em que esses profissionais pedem auxílio para problemas de programação ou trabalham colaborativamente em projetos de código aberto. "Esses fóruns apresentam uma excelente oportunidade para compartilhar conhecimento e fornecer um meio ideal para o aprendizado" (AHMED; SRIVASTAVA, 2017, p. 1, tradução nossa). Alguns sites populares entre profissionais de software são: Stack Overflow ${ }^{5}$, Github $^{6}$, Code Project ${ }^{7}$, entre outros. Calefato, Lanubile e Novielli (2018) ressaltam que a obtenção de informação nessas comunidades virtuais depende muito da boa vontade dos demais membros em auxiliar o solicitante. É relevante frisar que, além dos votos dados pelos membros sobre o que consideram ser a melhor resposta, não há muitos meios de assegurar sua confiabilidade ou competência do respondente.

\footnotetext{
${ }^{5}$ Fonte: Stack Overflow. Disponível em: <https://pt.stackoverflow.com/>. Acesso em: 28 jan. 2019.

6 Fonte: GitHub. Disponível em: <https://github.com/>. Acesso em: 28 jan. 2019.

${ }^{7}$ Fonte: Code Project. Disponível em: <https://www.codeproject.com/>. Acesso em: 28 jan. 2019.
} 
Outra questão apurada é a carga de trabalho intensa desses profissionais. Este fator interfere nas práticas informacionais como barreira ao compartilhamento de informação, devido à falta de tempo (DAVENPORT; PRUSAK, 1998). Para Shropshire e Kadlec (2012), o stress é uma das razões para os profissionais de TIC deixarem a profissão.

Para Asgari, Jafari e Ramazani (2017), as causas de stress entre esses profissionais são: competitividade acirrada do mercado; complexidade do trabalho; necessidade de acompanhar a incessante evolução tecnológica. Além destes fatores, estes autores (2017) destacam que há pressão em relação ao tempo para concluir os projetos e que a relação com os clientes esbarra no problema da comunicação, que nem sempre é clara. Tendo sido identificadas algumas práticas informacionais no cotidiano dos desenvolvedores de software, é preciso verificar se estas se confirmam empiricamente e como agem sobre a cultura organizacional.

\section{Procedimentos metodológicos}

A presente pesquisa caracteriza-se como um estudo de casos múltiplos com enfoque qualitativo, estando, portanto, lastreada em dados empíricos acerca da relação dos profissionais desenvolvedores de software com a informação. Esse aspecto empírico será abordado em maiores detalhes posteriormente, na presente seção.

Primeiramente, destaca-se que o presente trabalho possui uma parcela teórica, desenvolvida por meio de uma pesquisa bibliográfica, caracterizada como uma revisão de literatura narrativa. Essa revisão utiliza uma abordagem qualitativa para a seleção de obras e autores de reconhecida relevância, e outros aportes teóricos que venham a colaborar para uma apreciação crítica do tema de pesquisa, diferindo da revisão de literatura sistemática, por não ser exaustiva nem seguir protocolos de seleção pré-definidos, servindo para dar suporte à contextualização do trabalho (UNIVERSIDADE ESTADUAL PAULISTA, 2015). Assim, efetuou-se, em abril de 2019, uma busca nas bases de dados Library and Information Science Abstracts (LISA), Web of Science - Clarivate Alanytics e Scientific Electronic Library Online (Scielo), bem como na Biblioteca da Faculdade de Filosofia e Ciências (FFC) da Universidade Estadual Paulista (UNESP). Os termos de busca empregados, nos idiomas português, inglês e espanhol, foram: práticas informacionais, desenvolvimento de software, fenomenologia, hermenêutica, cultura informacional, cultura organizacional e cultura profissional. Para a obtenção de resultados mais amplos, não foi definido nenhum intervalo de tempo a priori para a busca. Utilizando-se a abordagem qualitativa, efetuou-se a leitura inicial dos resumos dos trabalhos recuperados, selecionando-se aqueles que se coadunavam com o tema da presente pesquisa.

Em relação ao aspecto empírico do trabalho, como já referido, este se trata de um estudo de casos múltiplos. $O$ estudo de caso é passível de generalização analítica, demonstrando 
sua validade pela lógica da replicação dos resultados, em uma segunda ou terceira unidade de análise, não por critérios quantitativos estatísticos: "uma vez que tais replicações diretas tenham sido feitas, os resultados podem ser aceitos como um forte suporte para a teoria, mesmo que outras replicações não tenham sido realizadas" (YIN, 2009, p. 44, tradução nossa). Esse é um critério de validade qualitativo que se apoia na possibilidade de reproduzir os resultados, ainda que seja em uma quantidade reduzida de casos, mesmo que apenas dois ou três, como afirma, explícita e literalmente, o autor supracitado (2009). Esse método se presta para aprofundar ou expandir uma determinada teoria, embora não seja um retrato estatisticamente exato de toda uma população.

[...] estudos de caso, como experimentos, são generalizáveis para proposições teóricas e não para populações ou universos. Nesse sentido, o estudo de caso não [...] representa uma "amostra" e, ao fazer um estudo de caso, seu objetivo será expandir e generalizar teorias (generalização analítica) e não enumerar frequências (generalização estatística) (Op. cit., p. 15, tradução nossa).

Essa perspectiva qualitativa está no cerne da hermenêutica. Para Braida (1999), a hermenêutica é considerada fundamento geral das ciências humanas e sociais, caracterizando o 'paradigma da compreensão', que visa a interpretação dos significados intencionais subjacentes às ações humanas, em contraposição ao 'paradigma positivista', oriundo das ciências naturais, exatas e experimentais, que usa a quantificação e indução para explicar as causas dos fenômenos. O paradigma da compreensão questiona a validade dos métodos estatísticos/experimentais para entender os fenômenos humanos, demasiado complexos e mutáveis para se restringirem à elaboração de padrões com base matemática (BRAIDA, 1999). Nessa perspectiva, importa a apreensão da essência dos fenômenos, não sua quantificação.

$\mathrm{Na}$ presente pesquisa, o estudo de caso se presta a expandir uma compreensão das teorias de estudos de usuários da informação e, particularmente, das práticas informacionais, para contemplar as especificidades do contexto dos desenvolvedores de software, ainda que as características observadas não tenham uma probabilidade matematicamente definida de se repetirem tal qual descrito em todas as demais empresas de software.

Em relação às técnicas de coleta de dados, foram realizadas entrevistas com gestores e desenvolvedores de software, em duas empresas, a fim de verificar valores, crenças e práticas em relação à informação e ao conhecimento, interpretando os significados subjacentes em seu discurso. O roteiro de entrevistas com os gestores enfocou a descoberta de valores, ações e políticas organizacionais voltadas ao compartilhamento, uso e registro de informação e conhecimento, baseados, sobretudo, nos comportamentos e valores da cultura informacional 


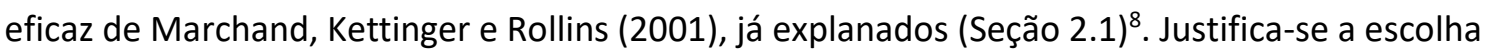
de entrevistar primeiramente os gestores, pois estes têm uma visão mais holística do trabalho também por sua função de difundir e reforçar a adesão aos valores organizacionais oficiais, e até mesmo de criação desses valores, quando o gestor é também o fundador da empresa (SCHEIN, 2007).

Os roteiros de entrevista com os colaboradores das empresas ${ }^{9}$ visaram aprofundar 0 entendimento sobre os valores organizacionais voltados à informação e ao conhecimento, coletados na etapa anterior. Enfocou-se a aclaração das contradições evidenciadas no discurso dos gestores, evidenciando as certezas tácitas compartilhadas, como define Schein (2007). Apurou-se também a forma como fatores típicos da cultura profissional dos desenvolvedores de software, a preponderância do uso da Internet e a rotina estafante (Seção 2.2), interfeririam em sua relação com a informação e o conhecimento.

Justifica-se a escolha das empresas por encaixarem-se no perfil da empresa típica de software brasileira, nos quesitos porte e segmento de atuação. Ambas as empresas selecionadas dedicam-se à elaboração de softwares empresariais, atividade principal de 63,32\%, das organizações de TI no Brasil (ASSOCIAÇÃO PARA PROMOÇÃO DA EXCELÊNCIA DO SOFTWARE BRASILEIRO, 2018). Ademais, as referidas organizações também se enquadram no perfil de pequenas e médias empresas (PME). No setor de TICs, especialmente, pode-se estimar uma grande proporção de MPE, visto que $77 \%$ dos afiliados da Associação Brasileira das Empresas de Software (2019) são assim caracterizados.

Por fim, as empresas selecionadas estão inseridas em relevantes polos tecnológicos, visto que uma delas, doravante denominada empresa $Y$, se situa no município paulista de Marília, detentor de um dos cinco Arranjos Produtivos Locais de TI do estado de São Paulo (APLTI). A segunda empresa, doravante denominada empresa Z, situa-se no município paulista de Garça, polo da indústria eletroeletrônica e de segurança eletrônica (GARÇA, PREFEITURA MUNICIPAL, 2018).

Reitera-se que a escolha de dois casos é adequada aos propósitos de generalização analítica, conforme já exposto. Desse modo, pôde-se identificar a repetição de padrões nas falas dos entrevistados, que revelam aspectos culturais em comum. Para realizar a análise dos dados obtidos, adotou-se o método 'Análise de Conteúdo', mais especificamente a técnica de análise categorial de Bardin (2004), cujas categorias, formadas por temas, foram estabelecidas a

\footnotetext{
${ }^{8} \mathrm{O}$ roteiro da entrevista com os gestores está disponível no Apêndice $E$, da dissertação de mestrado de Souza (2019, p. 250).

${ }^{9}$ Os roteiros das entrevistas com os colaboradores estão disponíveis nos Apêndices J e V , da dissertação de mestrado de Souza (2019, p. 260; 278).
} 
posteriori. O tema refere-se a elementos textuais que formam um sentido completo, como frases ou parágrafos; já a formação de categorias a posteriori significa que os temas foram reunidos por afinidade e, posteriormente, categorizados ou rotulados (BARDIN, 2004).

As entrevistas com os gestores das respectivas empresas, $\mathrm{Y}$ e Z, tiveram duração média de uma hora, enquanto cada sessão de entrevistas com os demais colaboradores durou em média 20 minutos. A empresa Y possui cerca de 130 colaboradores e uma trajetória de 20 anos na elaboração de sistemas empresariais. A Empresa Z possui 18 colaboradores, atuando há quase 30 anos com sistemas empresariais e consultoria em TI.

Na empresa $Y$, foram entrevistados um gestor e sete colaboradores, enquanto na empresa Z, um gestor e quatro colaboradores. Os sujeitos aceitaram voluntariamente participar da pesquisa em resposta a um convite que lhes foi enviado por e-mail. A coleta de dados na empresa $Y$ foi efetuada entre maio e julho de 2018 , enquanto na empresa $Z$, entre outubro e dezembro de 2018. As entrevistas foram efetuadas em salas reservadas pelas organizações especialmente para este fim, ficando entrevistador e entrevistados a sós, minimizando ruídos ou interferências externas que pudessem dificultar a livre expressão dos pesquisados.

$\mathrm{Na}$ análise e interpretação dos resultados foi também utilizada a fenomenologia de Paul Ricoeur com função heurística. Conforme Rendón-Rojas e Hernández-Salazar (2010), uma heurística é um conjunto de diretrizes que servem para guiar o olhar do pesquisador, apontar caminhos e ajudá-lo a interpretar a realidade sem, contudo, determinar quaisquer técnicas ou métodos específicos.

\section{Resultados e discussão}

Inicialmente, efetuou-se uma entrevista com o Diretor de Desenvolvimento da Empresa $Y$, para apurar os valores referentes às práticas informacionais, que são inculcados nos desenvolvedores de software. Valores estes que são componentes da cultura informacional e evidência de sua essência. Buscou-se, também, trazer à tona possíveis contradições nesses valores, pois, conforme Schein (2007), a confrontação entre os valores aparentes e possíveis contradições permite um vislumbre das reais práticas organizacionais. A partir de uma perspectiva inspirada na fenomenologia e na hermenêutica, trechos do discurso do entrevistado foram interpretados como categorias que revelam crenças construídas coletivamente. Ressaltase que, em virtude de as categorias terem sido elaboradas a posteriori, ou seja, os excertos da entrevista foram primeiramente agrupados por afinidade de temas, e posteriormente rotulados, existe a possibilidade de algumas dessas categorias serem diferentes das da empresa $Z$. Contudo, pode haver, também, categorias de valores culturais semelhantes entre as empresas Y e Z. 
As categorias semelhantes podem representar elementos de uma cultura profissional em comum, enquanto categorias distintas podem representar elementos peculiares a cada cultura organizacional. Argumenta-se, ainda, que a identificação de categorias comuns entre as empresas Y e Z e seu respaldo pela literatura científica podem reforçar a hipótese de que sejam de fato valores da cultura profissional, conforme o conceito de generalização analítica, já discutido (Seção 3). Assim, no âmbito da generalização analítica, a escolha de dois casos é adequada para expandir aportes teóricos dos estudos de usuários para tratar do contexto dos desenvolvedores de software, mesmo que não haja uma garantia estatisticamente definida que as características observadas se reproduzirão fielmente em todos os possíveis casos (YIN, 2009).

Os valores informacionais expostos e suas aparentes contradições na Empresa $Y$ são exibidos no Quadro 1. O referido quadro se divide em duas colunas, sendo a da esquerda referente aos valores organizacionais afirmados pelo entrevistado (valores expostos) e a da direita referente às contradições evidenciadas em relação a esses valores, em consonância com a metodologia de Schein (2007) para identificação das certezas tácitas compartilhadas. Ratificase que o embasamento teórico que fundamentou as entrevistas e, por consequência, influenciou a elaboração dos quadros e das categorias a posteriori, foi o modelo de cultura informacional eficaz de Marchand, Kettinger e Rollins (2007).

Quadro 1: Valores informacionais expostos e suas aparentes contradições na Empresa Y.

\begin{tabular}{|c|c|}
\hline Valores Aparentes & Possíveis Contradições nos Valores Aparentes \\
\hline Transmissão eficaz de informação ao usuário leigo & Possível déficit na compreensão de informação \\
\hline $\begin{array}{l}\text { "Uma comunicação com o cliente em linguagem que ele } \\
\text { compreenda, sem utilizar termos técnicos". }\end{array}$ & $\begin{array}{l}\text { "Eles têm dificuldades de interpretar tanto as situações } \\
\text { quanto os requisitos de sistema. [...]". }\end{array}$ \\
\hline Sigilo e ética informacionais & Possível déficit na obtenção de conhecimentos \\
\hline $\begin{array}{l}\text { "Os profissionais têm acesso [...] à estratégia de mercado } \\
\text { do cliente. Este termo serve, também, para evitar que o } \\
\text { profissional forneça dados dessa estratégia ao } \\
\text { concorrente". }\end{array}$ & $\begin{array}{l}\text { "[...] o empenho das pessoas em colaborar [participando } \\
\text { das palestras] era baixo". }\end{array}$ \\
\hline Coesão nas equipes de trabalho & Possível déficit na elaboração de documentação \\
\hline $\begin{array}{l}\text { Tentamos adotar boas práticas na gestão de projetos e de } \\
\text { equipes. [...] Temos, por exemplo, um campeonato de } \\
\text { sinuca. Neste contexto, o pessoal do financeiro, da } \\
\text { programação e até da limpeza podem interagir. }\end{array}$ & $\begin{array}{l}\text { "[...] pecamos na falta de uma cobrança mais ativa neste } \\
\text { respeito". "Todos têm a ideia de que a documentação vai } \\
\text { burocratizar mais e trazer mais custos para o projeto". }\end{array}$ \\
\hline Acessibilidade na obtenção de informação & Possivel postura punitivista \\
\hline $\begin{array}{l}\text { Começamos a aplicar a metodologia Evolution para } \\
\text { disseminar conhecimento sobre nossos produtos e também } \\
\text { sobre aspectos de negócio [...]. Podiam comparecer [...] } \\
\text { mesmo que o assunto não fosse diretamente ligado à sua } \\
\text { função. }\end{array}$ & \multirow{5}{*}{$\begin{array}{l}\text { "Algumas pessoas no RH acham que deveríamos impor } \\
\text { penalidades de maneira mais firme." }\end{array}$} \\
\hline Socialização da informação e do conhecimento & \\
\hline $\begin{array}{l}\text { "É um momento para }[\ldots . .] \text { fazer um brainstorming }[\ldots . .] \text {. Se } \\
\text { for para falar sobre projetos, pode fazer quantos intervalos } \\
\text { quiser". }\end{array}$ & \\
\hline Registro da informação & \\
\hline "Prezamos a importância da documentaçã & \\
\hline
\end{tabular}




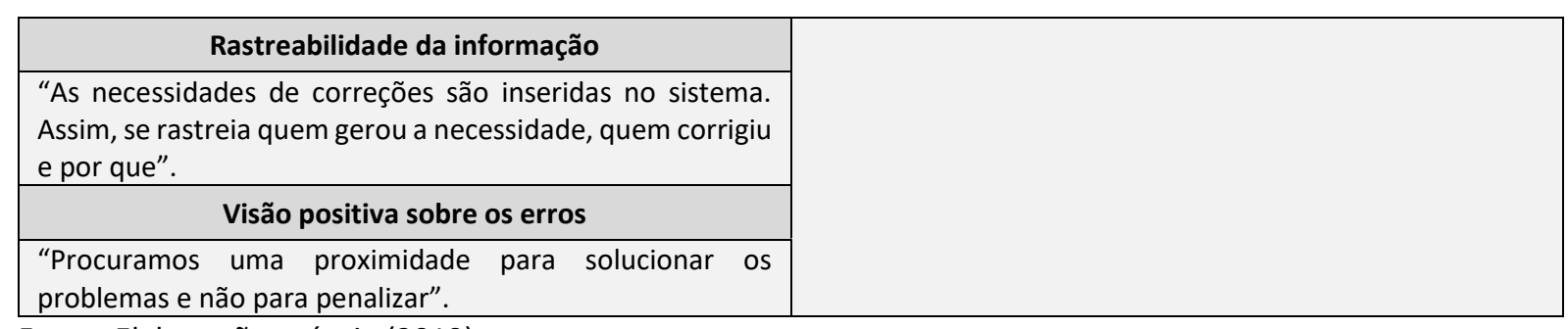

Fonte: Elaboração própria (2019).

Reitera-se que valores informacionais e cultura informacional não são rigorosamente sinônimos, contudo, os primeiros são componentes basilares e evidências da essência desta última, como já discutido na definição de cultura informacional apresentada anteriormente (Seção 1).

No Quadro 1: a categoria 'Acessibilidade na obtenção de informação' se opõe à categoria 'Possível déficit na obtenção de conhecimentos'; 'Registro da informação' é antagônica a 'Possível déficit na elaboração de documentação' e a 'Possível déficit na compreensão de informação'; 'Visão positiva sobre os erros' é antagônica a 'Possível postura punitivista'. Enfatiza-se que 'Registro da informação' e 'Possível déficit na compreensão de informação' se antagonizam no sentido em que a primeira afirma a valorização e consistência da documentação de software, enquanto que a última evidencia que a documentação de requisitos de software, que determina as características do sistema a ser desenvolvido, é de difícil compreensão para os programadores.

Entretanto, 'Transmissão eficaz de informação ao usuário leigo', 'Sigilo e ética informacionais', 'Coesão nas equipes de trabalho', 'Socialização da informação e do conhecimento', 'Rastreabilidade da informação', não apresentaram categorias antagônicas, $a$ priori. Embora o conjunto de categorias em que são se encontrou divergências a priori tenha maior possibilidade de representar os reais valores informacionais da organização, é preciso examinar mais a fundo as categorias que apresentaram contradições aparentes, quais as certezas tácitas compartilhadas subjacentes a elas.

No que tange à categoria 'transmissão eficaz de informação ao usuário leigo', verificouse a existência de uma preocupação com o relacionamento com o cliente, no sentido de traduzir o funcionamento do software em uma linguagem não técnica e acessível. Quanto à categoria 'sigilo e ética informacionais', em conformidade com o valor de 'integridade informacional', de Marchand, Kettinger e Rollins (2001), os colaboradores se comprometem, mediante assinatura de um termo, a não revelar detalhes dos negócios dos clientes.

Sobre a 'coesão nas equipes de trabalho', afirmou-se que a Empresa Y possui políticas para incrementar a socialização entre os sujeitos. Essa categoria influencia diretamente na 'socialização da informação e do conhecimento'. É imprescindível que as pessoas tenham 
oportunidade de interagir informalmente para que se conheçam melhor, estabeleçam uma relação de confiança e, assim, possam compartilhar informação e conhecimento mais efetivamente (DAVENPORT; PRUSAK, 1998; MARCHAND; KETTINGER; ROLLINS, 2001; TAKEUCHI, NONAKA, 2008).

Com relação à 'acessibilidade na obtenção de informação', afirmou-se que cursos e palestras sobre assuntos tecnológicos e organizacionais providos pela empresa são abertos a toda comunidade organizacional, independentemente de setor ou cargo. Essa postura provê aos sujeitos uma visão mais holística do negócio da Empresa Y. É uma tática semelhante à observada por Takeuchi e Nonaka (2008) nas empresas japonesas, nas quais os colaboradores, antes de alcançar cargos de gerência, devem trabalhar em vários e distintos setores, para ampliarem suas perspectivas e construírem um sólido repertório de conhecimentos.

Em conformidade com o aspecto referente à formalização de Marchand, Kettinger e Rollins (2001), relatou-se que a documentação de software é prezada na Empresa $Y$, mais especificamente na categoria 'registro da informação'. Referente à 'rastreabilidade da informação', atributo essencial à qualidade da documentação de software, conforme Zhi et al. (2015), observou-se que, quando há necessidade de alteração ou correção de código, detalhes sobre o motivo da alteração, autor da alteração, data e outros dados são registrados para fins de controle do histórico de evolução dos projetos.

Concernente à categoria 'visão positiva sobre os erros', evidenciou-se que os lapsos cometidos pelos programadores, algo não raro de ocorrer em projetos complexos como os de software, são tratados de modo compreensivo e construtivo. Essa tolerância é aspecto essencial da 'transparência informacional' mencionada por Marchand, Kettinger e Rollins (2001).

Além dos elementos positivos, foram analisados alguns possíveis conflitos de valores na Empresa Y. Na categoria 'possível déficit na compreensão de informação', expressou-se uma relativa dificuldade de os programadores compreenderem o que lhes é requerido nas atividades de projetos, principalmente no que se refere à documentação de requisitos, que determina justamente os requisitos de funcionamento do software a ser elaborado. Outra questão é que, apesar de a empresa prover palestras abertas a todos os colaboradores, na categoria 'possível déficit na obtenção de conhecimentos', constatou-se um comparecimento abaixo do esperado.

Mesmo se tendo afirmado que a documentação é prezada, a categoria 'possível déficit na elaboração de documentação' indica certa resistência em documentar, pois esta tarefa seria compreendida como algo que toma tempo, que seria mais bem empregado na produção do software. Essa postura contraria a afirmação de Zhi et al. (2015), segundo a qual há relevância da documentação para prover informação precisa sobre projetos de software e servir como ferramenta de comunicação entre os membros da equipe de desenvolvimento. A documentação 
aqui discutida refere-se a registros, diagramas e afins, que auxiliam na compreensão da estrutura e configurações internas do software, como já conceituado anteriormente (seção 2.2). A documentação é um registro sobre a evolução dos projetos, que podem ter uma vida útil longa, como no caso do principal sistema da Empresa $Y$, que está no mercado desde sua fundação. Por fim, sobre a 'possível postura punitivista', afirmou-se que, apesar de uma relativa tolerância quanto ao cometimento de erros, alguns membros administrativos defenderiam maior rigidez com os eventuais lapsos dos colaboradores.

É relevante salientar que algumas das categorias de valores aparentes, já discutidas, são semelhantes às identificadas no trabalho de Souza e Moraes (2018), acerca dos fatores intervenientes na motivação para o compartilhamento de conhecimentos tácitos, a saber: espírito de equipe; livre acesso à informação e ao conhecimento; compartilhamento efetivo da informação e do conhecimento; tolerância aos erros. Contudo, esses autores concentram-se nos aspectos positivos das práticas informacionais e não consideram o problema da contradição nos valores aparentes.

É preciso, também, esclarecer as aparentes divergências identificadas no discurso do entrevistado, bem como compreender os motivos por trás dos valores e práticas adotados na empresa. Assim, seguindo as diretrizes de Schein (2007), foram conduzidas entrevistas com os colaboradores, programadores e analistas de sistemas, para elucidar os elementos do núcleo da cultura organizacional. Dentre os 26 desenvolvedores de software da Empresa $Y, 7$ se dispuseram voluntariamente à entrevista.

Destaca-se que não se fez distinção em relação à especialidade dos profissionais, visto que, como pressuposto do presente trabalho, admite-se que os sujeitos que desenvolvem softwares, quer seja criando código-fonte, bases de dados, efetuando integração com sistemas externos, e uma miríade de outras funções possíveis, comungam de uma mesma cultura profissional, devido: à sua formação; aos valores partilhados; ao contexto de trabalho, influenciado pela rapidez e mudanças tecnológicas constantes; à características do setor de atuação das empresas. Admite-se que a cultura profissional em comum influencia a cultura e as práticas informacionais, como já discorrido (Seção 2.2). O próprio conceito de cultura denota a existência de valores partilhados que transcendem as diferenças individuais. São buscados fatores gerais que influenciam as práticas informacionais dos desenvolvedores de software, que vão além das nuances decorrentes de suas áreas de especialização ou função nos projetos. No Quadro 2, apresenta-se a interpretação dos valores presentes no discurso dos sujeitos pesquisados. 
Quadro 2: Evidências das certezas tácitas compartilhadas quanto à informação e ao conhecimento na empresa $Y^{10}$

\begin{tabular}{|c|c|}
\hline \multicolumn{2}{|c|}{ Categorias sobre certezas tácitas compartilhadas quanto à informação e ao conhecimento } \\
\hline $\begin{array}{l}\text { Utilização da } \\
\text { Internet para } \\
\text { obtenção de } \\
\text { informação } \\
\text { suplementar. }\end{array}$ & $\begin{array}{l}\text { - "Uso a Internet para dar uma lapidada, aperfeiçoar o trabalho" (Entrevistado B). } \\
\text { - "É bom ver pessoas que tiveram a mesma dificuldade e como resolveram os problemas [...]" } \\
\text { (Entrevistado D)". } \\
\text { - "As novas tecnologias tornam a Internet relevante como fonte de informação. Eu a utilizo para } \\
\text { me atualizar" (Entrevistado G). }\end{array}$ \\
\hline $\begin{array}{l}\text { Elaboração de } \\
\text { documentação } \\
\text { sucinta. }\end{array}$ & $\begin{array}{l}\text { - "[...] a documentação é bem pontual. No Scrum, documentamos todos os passos que fizemos } \\
\text { para executar as tarefas, para caso surja algum problema, e para a gente lembrar como fez, por } \\
\text { que fez daquela forma" (Entrevistado D). } \\
\text { - "Sempre que faço um check-in do código, escrevo um comentário falando o que foi } \\
\text { desenvolvido, porque foi feita uma alteração no código [...]" (Entrevistado E). } \\
\text { - "Faço alguns casos de uso para o pessoal do teste [...] quando há alguma alteração, para } \\
\text { poderem entender o impacto no sistema [...]" (Entrevistado E). }\end{array}$ \\
\hline $\begin{array}{l}\text { Possíveis } \\
\text { deficiências na } \\
\text { documentação } \\
\text { externa. }\end{array}$ & $\begin{array}{l}\text { - "Os frameworks que utilizo têm informações que não são claras. Os exemplos dados na } \\
\text { - "Tocumentação nem sempre funcionam" (Entrevistado A). } \\
\text { - "Quanto à documentação de integração, cada plataforma [de outras empresas] trabalha de um } \\
\text { jeito, e a documentação nem sempre é clara" (Entrevistado D). }\end{array}$ \\
\hline $\begin{array}{l}\text { Possíveis } \\
\text { deficiências na } \\
\text { documentação } \\
\text { interna. }\end{array}$ & $\begin{array}{l}\text { - "A documentação interna fica mais restrita ao MER (Modelo Entidade-Relacionamento)" } \\
\text { (Entrevistado A). } \\
\text { - "Às vezes acontece de alguém resolver problemas e não registrar. A falta de documentação do } \\
\text { fluxo como um todo às vezes prejudica, principalmente os mais novos" (Entrevistado D). } \\
\text { - "Documentação antiga é mais complicado, porque as coisas mudam e ela pode não estar } \\
\text { atualizada" (Entrevistado E). }\end{array}$ \\
\hline $\begin{array}{l}\text { Possíveis } \\
\text { dificuldades na } \\
\text { comunicação } \\
\text { escrita. }\end{array}$ & $\begin{array}{l}\text { - "Sim, é difícil. É porque a gente tem uma linha de raciocínio que pode ser diferente da de quem } \\
\text { vai ler" (Entrevistado B). } \\
\text { - "Às vezes você gasta tempo documentando e ninguém usa, ou só uma parte das pessoas } \\
\text { entende o registro" (Entrevistado D). } \\
\text { - "Algumas vezes é difícil me expressar. É mais fácil pensar do que escrever o que a gente está } \\
\text { tentando explicar" (Entrevistado G). }\end{array}$ \\
\hline $\begin{array}{l}\text { Acessibilidade } \\
\text { para socialização } \\
\text { de } \\
\text { conhecimentos. }\end{array}$ & $\begin{array}{l}\text { - "Quando você troca ideias com o colega, um cara que já sabe, você consegue evoluir muito mais } \\
\text { rápido do que quando tenta sozinho" (Entrevistado B). } \\
\text { - "Não tenho receio, sempre pergunto quando tenho dúvida. Os colegas estão sempre dispostos } \\
\text { a ajudar" (Entrevistado E). } \\
\text { - "Todos se ajudam. Não temos este receio de perguntar ao colega" (Entrevistado F). }\end{array}$ \\
\hline $\begin{array}{l}\text { Empenho pela } \\
\text { compreensão da } \\
\text { perspectiva do } \\
\text { usuário leigo }\end{array}$ & $\begin{array}{l}\text { - "É tranquilo exemplificar o que imagino, a não ser quando tenho que me comunicar com o } \\
\text { cliente, usando termos técnicos" (Entrevistado A). "[...] não se pode misturar inglês com } \\
\text { português, tem que ser a linguagem mais simples possível, para traduzir para o usuário leigo o } \\
\text { funcionamento do sistema" (Entrevistado F). }\end{array}$ \\
\hline $\begin{array}{l}\text { Carência de } \\
\text { tempo. }\end{array}$ & $\begin{array}{l}\text { - "É difícil descansar a mente, você não consegue desligar. Você descansa o corpo, a mente não" } \\
\text { (Entrevistado A). } \\
\text { - "Tem as pressões do dia a dia, mas nada que afete a saúde" (Entrevistado B). } \\
\text { - "Sim, bastante. Apesar de não ter muito contato com o cliente, tenho que ajudar os colegas. Às } \\
\text { vezes não consigo ajudar o colega como gostaria porque tenho meus afazeres. Às vezes é } \\
\text { desgastante" (Entrevistado F). }\end{array}$ \\
\hline $\begin{array}{l}\text { Possível } \\
\text { hesitação em } \\
\text { ampliar o } \\
\text { repertório de } \\
\text { conhecimentos } \\
\text { não técnicos. }\end{array}$ & $\begin{array}{l}\text { - "Depende do tema [da palestra], o pessoal de desenvolvimento não faz muita questão de } \\
\text { participar de coisas de Humanas" (Entrevistado B). } \\
\text { - "Se tem algo de gestão a quantidade de pessoas que você atinge é menor. [...] Para gestão os } \\
\text { programadores não têm muito interesse" (Entrevistado C). } \\
\text { - "É meio fraca a participação. Às vezes as pessoas acham que o tema não é relevante naquele } \\
\text { momento. Depende do tema" (Entrevistado D). } \\
\text { - "Tendemos a participar de palestras que têm mais a ver com dia a dia da gente, como palestras } \\
\text { sobre Delphi, a linguagem que usamos" (Entrevistado E). }\end{array}$ \\
\hline $\begin{array}{l}\text { Objetividade na } \\
\text { aquisição de }\end{array}$ & $\begin{array}{l}\text { - "Eu participo porque quero aprender mais, quero ter conhecimento, quero crescer. A empresa } \\
\text { não obriga a fazer treinamentos. Faço porque quero crescer profissionalmente" (Entrevistado } \\
\text { E). }\end{array}$ \\
\hline
\end{tabular}

${ }^{10}$ Por razões de concisão, apenas algumas falas foram transcritas. 


\begin{tabular}{|c|c|}
\hline $\begin{array}{l}\text { conhecimentos } \\
\text { técnicos }\end{array}$ & $\begin{array}{l}\text { - "Aqui o nível de participação nos treinamentos é alto, pelo sistema ser bem complexo. Apenas } \\
\text { poucas pessoas têm o conhecimento global do sistema. Tentamos disseminar este } \\
\text { conhecimento, passar o que cada um sabe para todos" (Entrevistado F). } \\
\text { - "Em treinamentos internos, em horário de trabalho, vai bastante gente" (Entrevistado G). }\end{array}$ \\
\hline $\begin{array}{l}\text { Precaução para } \\
\text { evitar erros. }\end{array}$ & $\begin{array}{l}\text { - "Há sempre um medo de estragar um ambiente de programação, excluir um banco de dados de } \\
\text { cliente" (Entrevistado A). } \\
\text { - "Na parte de operações, temos um pouco de receio. Por isto testamos bastante o código" } \\
\text { (Entrevistado E). } \\
\text { - "Acho que todo mundo tem receio de errar, ainda mais quando você mexe com a parte fiscal e } \\
\text { financeira de uma empresa. Um erro pode significar perdas financeiras, processos" (Entrevistado } \\
\text { F). }\end{array}$ \\
\hline $\begin{array}{l}\text { Aprendizagem } \\
\text { por meio dos } \\
\text { erros. }\end{array}$ & $\begin{array}{l}\text { - "Os erros mais simples, o pessoal te chama e mostra como fazer corretamente" (Entrevistado } \\
\text { A). } \\
\text { - "Te procuram para saber sobre o erro e perguntam por que fez daquela forma. Eles te explicam } \\
\text { como fazer certo. Não é bronca. É bem tranquilo" (Entrevistado E). } \\
\text { - "Eles chamam e mostram como deve ser feito, explicam, instruem. É no sentido de ajudar, não } \\
\text { de punir [...]" (Entrevistado G). }\end{array}$ \\
\hline
\end{tabular}

Fonte: elaborado pelos autores (2019).

Referente à categoria 'utilização da Internet para obtenção de informação suplementar', a intensa utilização desta fonte de informação, identificada como um traço da cultura profissional dos programadores na literatura científica (AHMED; SRIVASTAVA, 2017; CALEFATO; LANUBILE; NOVIELLI, 2018), confirmou-se na empresa pesquisada. Os entrevistados afirmaram que os fatores que mais contribuem para o uso da Web são: ter acesso às experiências de outros membros da comunidade profissional para a resolução de problemas e manter-se atualizado em relação aos avanços tecnológicos da área. Esse uso construtivo das possibilidades presentes na Internet, portanto, vai além do pernicioso copiar e colar códigos prontos.

Quanto à 'elaboração de documentação sucinta', apurou-se que há uma visão prática, preferindo-se elaborar registros curtos para auxiliar nas tarefas mais imediatas. Contudo, a categoria 'possíveis deficiências na documentação interna' indica que essa documentação pode se restringir a poucos elementos, como o Modelo Entidade Relacionamento (MER), referente à base de dados. Argumenta-se que: uma documentação demasiado sucinta pode não permitir uma visão holística do projeto; soluções de problemas nem sempre são registradas; e documentações de projetos mais longevos podem não estar suficientemente atualizadas.

Esclarecendo a afirmação do Diretor de Desenvolvimento, de que algumas vezes os programadores teriam certa dificuldade para interpretar documentações de requisitos, a categoria 'possíveis dificuldades na comunicação escrita' evidencia que alguns entrevistados consideram um tanto desafiador expressar detalhes complexos de software na escrita. A categoria 'possíveis deficiências na documentação externa' mostra que a documentação de terceiros, manuais de linguagens e de integração com sistemas de outras empresas, comumente possuem inconsistências. Os problemas com a documentação não são específicos da Empresa Y, mas uma característica deste contexto profissional (ZHI et al., 2015; BALLE et al., 2018). 
Outro aspecto da cultura profissional que se confirma é o passo acelerado do trabalho que, de certa forma, imprime um desgaste aos profissionais de TIC. A categoria 'carência de tempo' evidencia uma rotina atarefada, em que o volume de afazeres determina maior ênfase na produtividade, interferindo inclusive no tempo disponível para auxiliar os colegas. Pode-se, ainda, inferir o impacto dessa relativa carência de tempo sobre a atividade de documentação. Embora autores como Asgari, Jafari e Ramazani (2017) alertem sobre a influência da pressão do tempo sobre os níveis de stress na TI, os entrevistados afirmam que isso não chega a causar-lhes danos à saúde.

A relativa inconsistência no registro de informações é compensada com o compartilhamento informal de conhecimentos de colega para colega, como mostra a categoria 'acessibilidade para socialização de conhecimentos'. Ainda que a socialização seja essencial para o compartilhamento da experiência adquirida no trabalho, a formalização e o registro são essenciais para ampliar esse saber por toda a organização (TAKEUCHI; NONAKA, 2008) e para a formação de uma memória a qual se poderá recorrer quando necessário.

Concernente ao depoimento do Diretor de Desenvolvimento sobre uma participação abaixo do esperado em cursos e palestras, a categoria 'possível hesitação em ampliar o repertório de conhecimentos não técnicos' ressalta que isto pode estar relacionado a um menor interesse em temas de gestão, comportamento e correlatos. A categoria 'objetividade na aquisição de conhecimentos técnicos' mostra uma preferência por temas tecnológicos, nos quais os sujeitos vejam explicitamente uma utilidade para sua atuação profissional e carreira a médio e longo prazo. Contudo, é importante conhecer os fatores que impactam na vida organizacional, facilitando a comunicação com o cliente, cuja perspectiva é um tanto árdua de se 'traduzir', como expõe a categoria 'empenho pela compreensão da perspectiva do usuário leigo'.

Por fim, no que se refere à transparência informacional de Marchand, Kettinger e Rollins (2001), a categoria 'aprendizagem por meio dos erros' mostra que os lapsos são entendidos de modo positivo, sem represálias, e são considerados oportunidades para ganhar experiência. A categoria 'precaução para evitar erros' expõe que o receio de cometer lapsos não provém necessariamente do temor de punições, mas da consciência de evitar problemas financeiros e/ou judiciais para a empresa.

Souza e Moraes (2018) identificaram também algumas categorias referentes à visão dos desenvolvedores de software sobre a aquisição, utilização e compartilhamento do conhecimento, salientando apenas aspectos positivos: abertura para a comunicação face a face; concepção pragmática da obtenção de conhecimento; compreensão e empatia quanto aos erros. A categoria 'concepção pragmática da obtenção de conhecimento' corresponde à 
categoria 'Objetividade na aquisição de conhecimentos técnicos', discutida no presente trabalho.

É pertinente avaliar também os valores culturais quanto às práticas informacionais na Empresa Z. Assim, apresenta-se a compilação da entrevista com o Diretor da Empresa (Quadro 3). Apurou-se que, apesar de as empresas pesquisadas se situarem em municípios distintos e serem de portes distintos, há vários valores similares, expostos tanto no discurso dos gestores como dos colaboradores, reforçando a hipótese da influência de uma cultura profissional sobre o aspecto informacional, além das particularidades das culturas organizacionais.

Quadro 3: Resumo dos valores organizacionais relativos à informação e ao conhecimento na Empresa Z e suas possíveis divergências.

\begin{tabular}{|c|c|}
\hline Valores Abraçados & Possíveis Divergências nos Valores Abraçados \\
\hline Socialização da informação e do conhecimento & $\begin{array}{l}\text { Possível hierarquização na distribuição da } \\
\text { informação. }\end{array}$ \\
\hline $\begin{array}{l}\text { "Há a área da cozinha e o pátio externo para o pessoal } \\
\text { trocar ideias [...]. Podem interagir até na antessala ou } \\
\text { no pátio, fora da empresa". "Se o programador tiver } \\
\text { dificuldades, ele pode ser ensinado por alguém de } \\
\text { mais conhecimento [...]". }\end{array}$ & $\begin{array}{l}\text { "Há uma certa hierarquia. Os programadores são } \\
\text { divididos em equipes e cada equipe tem seu } \\
\text { coordenador. A informação vem do topo da } \\
\text { hierarquia e é repassada aos coordenadores, e estes } \\
\text { repassam aos desenvolvedores". }\end{array}$ \\
\hline $\begin{array}{l}\text { Incentivo ao aperfeiçoamento da formação } \\
\text { profissional. }\end{array}$ & Possível supervisão informacional estrita \\
\hline $\begin{array}{l}\text { "Se eu preciso de um profissional certificado pela } \\
\text { Microsoft, eu pago o curso e a prova. Se ele tira a } \\
\text { certificação, ele recebe uma gratificação mensal no } \\
\text { holerite [...]". }\end{array}$ & $\begin{array}{l}\text { "Ele é registrado, monitorado e gravado, desde as } \\
\text { conversas telefônicas até os sites acessados". }\end{array}$ \\
\hline Registro da informação & Possível déficit na elaboração de documentação \\
\hline $\begin{array}{l}\text { "Isto tudo segue uma normativa de qualidade, com } \\
\text { documentações, atas, registros". "Temos os analistas } \\
\text { que, junto com a qualidade, elaboram o documento } \\
\text { [...] para o desenvolvedor realizar a tarefa". }\end{array}$ & \multirow{9}{*}{$\begin{array}{l}\text { "O programador não documenta. Não adianta. Ele já } \\
\text { recebe o papel com tudo o que tem que fazer, porque } \\
\text { às vezes o programador não tem aquela visão ampla. } \\
\text { Assim fica mais ágil". }\end{array}$} \\
\hline Sigilo e ética informacionais & \\
\hline $\begin{array}{l}\text { "Eles assinam um termo de sigilo [...] porque lidam } \\
\text { com informações de clientes". }\end{array}$ & \\
\hline Rastreabilidade da informação & \\
\hline $\begin{array}{l}\text { "Quando o erro passou [...] é aberto um processo do } \\
\text { Programa de Melhoria Contínua. Aí será verificado } \\
\text { por que o colaborador deixou passar o erro. Podemos } \\
\text { identificar em que módulo ocorreu o erro. É uma } \\
\text { triagem [...]". }\end{array}$ & \\
\hline Visão positiva sobre os erros & \\
\hline “Isto não é para punir. É para melhorar”. & \\
\hline Uniformização de processos & \\
\hline $\begin{array}{l}\text { "Temos padrões de desenvolvimento e todo } \\
\text { programador deve obedecer a estes padrões". }\end{array}$ & \\
\hline
\end{tabular}

Fonte: elaborado pelos autores (2019).

No Quadro 3: a categoria 'Socialização da informação e do conhecimento' apresenta contradição com as categorias ‘Possível hierarquização na distribuição da informação' e 'Possível 
supervisão informacional estrita'; 'Registro da informação' apresenta contradição com 'Possível déficit na elaboração de documentação'. Reitera-se que o contexto favorável à socialização da informação e do conhecimento requer uma estrutura hierárquica menos rígida, preferencialmente mais planificada, bem como um ambiente relativamente descontraído, que permita criar laços de confiança e companheirismo entre os sujeitos organizacionais (DAVENPORT; PRUSAK, 1998; TAKEUCHI; NONAKA, 2008; SOUZA, MORAES, 2018). 'Incentivo ao aperfeiçoamento da formação profissional', 'Sigilo e ética informacionais', 'Rastreabilidade da informação', 'Visão positiva sobre os erros' e 'Uniformização de processos' não apresentaram categorias antagônicas a priori.

Alguns dos valores aparentes que coincidem nas falas dos gestores das Empresas $\mathrm{Y}$ e $\mathrm{Z}$ são: socialização da informação e do conhecimento; registro da informação; sigilo e ética informacionais; rastreabilidade da informação; visão positiva sobre os erros. Como essas categorias de valores na Empresa Z possuem um teor semelhante aos já abordados em relação à Empresa $Y$, seria redundante discuti-los novamente. Entretanto, dois valores aparentes constam somente na avaliação da Empresa Z, evidenciando que eles podem ser elementos intrínsecos de sua própria cultura organizacional. Um desses valores refere-se ao 'incentivo ao aperfeiçoamento da formação profissional'. Segundo o Diretor da Empresa Z, dá-se muita ênfase à especialização dos colaboradores, por isso a própria empresa investe em cursos preparatórios e provas de certificação oficiais em desenvolvimento de software. Segundo o Diretor, aqueles que adquirem as certificações recebem um acréscimo no salário. Tal estratégia parece acertada em um contexto no qual as mudanças tecnológicas são frequentes.

Outro aspecto particular da Empresa Z é a 'uniformização de processos'. Conforme o Diretor, o código de programação é elaborado por meio de padrões específicos que aumentam sua organização e a eficiência no trabalho, facilitando inclusive sua manutenção.

Identificaram-se, também, possíveis contradições nos valores aparentes, e uma delas, que se assemelha com a Empresa Y, reside no 'possível déficit na elaboração de documentação'. Conforme o entrevistado, os programadores recebem documentos de requisitos dos analistas e simplesmente executam o que consta neles. Assim, a documentação não abordaria tanto os meandros internos do funcionamento do código, mas focaria naquilo que se requer que o software execute. Contudo, em virtude da complexidade inerente do sistema de software, quaisquer registros que expliquem sua estrutura interna seriam um valioso auxílio para os programadores.

Mais um fator considerado foi a 'possível hierarquização na distribuição da informação'. A informação parte da cúpula organizacional, passando para os líderes de equipes até chegar aos programadores, na base. Infere-se, assim, uma possível rigidez no modo como a informação 
é compartilhada na organização. Somando-se a essa percepção de rigidez está a categoria 'possível supervisão informacional estrita', pois foi relatado que os colaboradores são monitorados e gravados quando acessam a Internet e se comunicam ao telefone, sendo que cada funcionário pode acessar apenas os arquivos designados para sua função e cargo. Essas restrições podem representar uma medida válida de segurança, desde que não tolham demais os fluxos de informação.

É preciso verificar o significado dos valores aparentes e possíveis contradições, para apurar o que se confirma ou não, e qual a sua razão de ser. No Quadro 4, apresenta-se a compilação das falas de quatro profissionais voluntários entrevistados.

\section{Quadro 4: Evidências das certezas tácitas compartilhadas quanto à informação e ao conhecimento na Empresa Z}

\begin{tabular}{|c|c|}
\hline \multicolumn{2}{|r|}{ Categorias sobre certezas tácitas compartilhadas quanto à informação e ao conhecimento } \\
\hline $\begin{array}{l}\text { Preponderância } \\
\text { da utilização da } \\
\text { Internet para } \\
\text { obtenção de } \\
\text { informação. }\end{array}$ & $\begin{array}{l}\text { - "A Internet é útil para aprender novas tecnologias e novos métodos, porque a tecnologia muda a } \\
\text { todo momento [...]" (Entrevistado H). } \\
\text { - "Direto. Ela é a principal fonte de informação. Quando ela para, cai o mundo [...]" (Entrevistado I). } \\
\text { - "Quando vamos iniciar um novo projeto, usamos a Internet para conhecer novas tecnologias e } \\
\text { métodos" (Entrevistado K). }\end{array}$ \\
\hline $\begin{array}{l}\text { Perspicácia na } \\
\text { avaliação da } \\
\text { informação }\end{array}$ & $\begin{array}{l}\text { - "Ela disponibiliza muito conhecimento, mas você precisa saber pesquisar as fontes certas, porque } \\
\text { há muitas armadilhas" (Entrevistado H). }\end{array}$ \\
\hline $\begin{array}{l}\text { Acessibilidade } \\
\text { para } \\
\text { socialização de } \\
\text { conhecimentos. }\end{array}$ & $\begin{array}{l}\text { - "Se tiver alguém especializado por perto a gente vai buscar informação com esta pessoa [...]" } \\
\text { (Entrevistado H). } \\
\text { - "O positivo é que o pessoal que tem habilidade de comunicação passa informação para os outros." } \\
\text { (Entrevistado I). } \\
\text { - "Não importa se é um cara novo ou mais antigo, sempre compartilhamos os conhecimentos" } \\
\text { (Entrevistado K). }\end{array}$ \\
\hline $\begin{array}{l}\text { Empatia ao } \\
\text { requisitar } \\
\text { informação }\end{array}$ & $\begin{array}{l}\text { - "[...] mas temos esta consciência, se a pessoa estiver ocupada mesmo, não interrompo" } \\
\text { (Entrevistado H). } \\
\text { - "Porque não pode ficar no pé do cara o tempo todo. Nesta área tem que ser um pouco autodidata" } \\
\text { (Entrevistado I). } \\
\text { - "[...] quando a pessoa está meio sem tempo e você precisa de informações dela, às vezes você } \\
\text { acaba atrapalhando o serviço da pessoa" (Entrevistado K). }\end{array}$ \\
\hline $\begin{array}{l}\text { Possíveis } \\
\text { entraves na } \\
\text { socialização }\end{array}$ & $\begin{array}{l}\text { - "Quando a pessoa tem amizade com outra, ela normalmente vai sempre perguntar para o amigo } \\
\text { e não sabe que a pessoa do lado já pode ter resolvido o problema" (Entrevistado H). } \\
\text { - "Sempre tem uns que têm dificuldade de interagir" (Entrevistado I). } \\
\text { - "Mas os mais isolados acabam não obtendo muita informação e nem passando informação" } \\
\text { (Entrevistado I). }\end{array}$ \\
\hline $\begin{array}{l}\text { Elaboração de } \\
\text { documentação } \\
\text { sucinta. }\end{array}$ & $\begin{array}{l}\text { - "Só se for uma coisa muito complexa, acabo pondo comentários para explicar melhor" } \\
\text { (Entrevistado J). } \\
\text { - "Nossa documentação é feita por demanda. Nós elaboramos estórias com os dados de requisitos" } \\
\text { (Entrevistado K). } \\
\text { - "A gente usa uma ferramenta de controle de versão e adiciona a descrição das alterações da sprint } \\
\text { nessa ferramenta" (Entrevistado K). }\end{array}$ \\
\hline $\begin{array}{l}\text { Possíveis } \\
\text { déficits na } \\
\text { documentação } \\
\text { externa. }\end{array}$ & $\begin{array}{l}\text { - "Na API da Cielo, por exemplo, a documentação é mais rasa e dá mais trabalho. Varia muito" } \\
\text { (Entrevistado I). }\end{array}$ \\
\hline & $\begin{array}{l}\text { - "Mas no código antigo a documentação é escassa [...]" (Entrevistado H). } \\
\text { - "O negativo é que às vezes você não tem instrução para resolver uma solução específica" } \\
\text { (Entrevistado H). }\end{array}$ \\
\hline
\end{tabular}




\begin{tabular}{|c|c|}
\hline $\begin{array}{l}\text { documentação } \\
\text { interna. }\end{array}$ & $\begin{array}{l}\text { - "Não tem por que comentar no código. Antigamente sim, porque não tinha o controle de versão" } \\
\text { (Entrevistado K). }\end{array}$ \\
\hline $\begin{array}{l}\text { Conviç̧ão na } \\
\text { suficiência } \\
\text { semântica do } \\
\text { código de } \\
\text { programação. }\end{array}$ & $\begin{array}{l}\text { - "O código bem feito já serve como documentação" (Entrevistado H). } \\
\text { - "O Scrum prega que o código mesmo se explica" (Entrevistado I). } \\
\text { - "O nome dos métodos já é autoexplicativo. O código-fonte é a documentação viva" (Entrevistado } \\
\text { l). }\end{array}$ \\
\hline $\begin{array}{l}\text { Uniformização } \\
\text { de processos }\end{array}$ & $\begin{array}{l}\text { - "Nós usamos por padrão dividir as funcionalidades por cada camada de software. É mais fácil." } \\
\text { (Entrevistado I). } \\
\text { - "Mas com o código de dois anos para cá nós já usamos os novos padrões e é bem mais } \\
\text { compreensível" (Entrevistado K). }\end{array}$ \\
\hline $\begin{array}{l}\text { Entraves no } \\
\text { entendimento } \\
\text { do código } \\
\text { legado }\end{array}$ & $\begin{array}{l}\text { - "Quanto mais o código é antigo, mais difícil é" (Entrevistado H). } \\
\text { - "Os códigos-fonte mais antigos não tinham muitos padrões de projetos" (Entrevistado I). } \\
\text { - "O código antigo não seguia os padrões atuais. Aí chamamos um programador mais antigo para } \\
\text { ele esclarecer como funciona o código" (Entrevistado K). }\end{array}$ \\
\hline $\begin{array}{l}\text { Empenho para } \\
\text { interpretar a } \\
\text { perspectiva do } \\
\text { autor do código } \\
\text { de } \\
\text { programação }\end{array}$ & $\begin{array}{l}\text { - "Tem sempre aquele choque até você entrar no mundo do colega, porque é outro raciocínio" } \\
\text { (Entrevistado I). } \\
\text { - "[...] até você entender onde a mente do cara foi, é complicado" (Entrevistado I). }\end{array}$ \\
\hline $\begin{array}{l}\text { Táticas de } \\
\text { enfrentamento } \\
\text { do stress }\end{array}$ & $\begin{array}{l}\text { - "O stress faz parte do trabalho e você tem que estar preparado e saber lidar sem se desesperar" } \\
\text { (Entrevistado H). } \\
\text { - "Eu tenho um princípio de que, sempre que termino uma tarefa que tem desgaste mental, eu paro, } \\
\text { vou tomar um café [...]. Mas a gente já se acostumou com a pressão" (Entrevistado I). } \\
\text { - "Se você consegue gerenciar bem as demandas não estressa, se é uma coisa que você gosta de } \\
\text { fazer" (Entrevistado k). }\end{array}$ \\
\hline
\end{tabular}

Fonte: Elaboração própria (2019).

Quanto aos valores identificados no discurso dos entrevistados da Empresa Z, que são semelhantes aos da Empresa $Y$, destacam-se: preponderância da utilização da Internet para obtenção de informação; acessibilidade para socialização de conhecimentos; elaboração de documentação sucinta; possíveis déficits na documentação externa; possíveis deficiências na documentação interna; táticas de enfrentamento do stress. Quanto à 'preponderância da utilização da Internet para obtenção de informação', infere-se que a Web tem, possivelmente, um papel ainda mais crucial como fonte de informação na Empresa Z, como expõe um dos excertos desta categoria.

Semelhante ao que ocorre na Empresa $Y$, a categoria 'táticas de enfrentamento do stress' evidencia uma rotina acelerada e pressões sobre a produtividade. Como na outra empresa, as pressões caracterizam-se por um nível de stress moderado e os sujeitos enfatizam o modo como cada um cria seus próprios métodos para lidar com a tensão. As demais categorias já elencadas têm também um teor muito semelhante nas duas empresas.

Quanto aos valores peculiares à cultura organizacional da Empresa Z, destacam-se: perspicácia na avaliação da informação; empatia ao requisitar informação; possíveis entraves na socialização; convicção na suficiência semântica do código de programação; uniformização de 
processos; entraves no entendimento do código legado; empenho para interpretar a perspectiva do autor do código de programação.

Quanto à 'perspicácia na avaliação da informação', constatou-se que, embora a Internet seja uma fonte de informação muito utilizada, existe o entendimento de que nem todas as informações são necessariamente confiáveis, é preciso avaliá-las cuidadosamente. Referente à 'empatia ao requisitar informação', constatou-se que a rotina atarefada não representa necessariamente um entrave para compartilhar informações entre colegas, mas que os colaboradores, quando percebem que o colega está ocupado, são compreensivos e procuram por si mesmos buscar as informações que necessitam.

Com respeito à 'convicção na suficiência semântica do código de programação', relatouse que para os entrevistados é desnecessário registrar comentários sobre o funcionamento de trechos do complexo código de programação. Há uma crença de que essas instruções em linguagem não natural, que trazem subjacentes intrincadas funções lógicas e matemáticas, podem ser prontamente compreensíveis. Essa postura sobre os comentários, que são também uma forma de documentação, pode estar ligada à categoria 'empenho para interpretar a perspectiva do autor do código de programação', na qual os sujeitos afirmaram que é um tanto árduo decifrar o real intuito do código dos colegas, compreender seu funcionamento por meio da interpretação da linha de raciocínio do autor. Essa dificuldade ocorre principalmente com o código mais antigo, como mostra a categoria 'entraves no entendimento do código legado'. Contudo, a categoria 'uniformização de processos' confirma o uso de padrões na programação, o que, na visão dos colaboradores, torna o código mais atual, desenvolvido com esses padrões, menos difícil de analisar.

Finalmente, a categoria 'possíveis entraves na socialização' expõe que, apesar de os sujeitos afirmarem que existe liberdade para trocar informação e conhecimento via contatos pessoais, tanto com colegas como com superiores hierárquicos, existem aspectos que podem ser aperfeiçoados. Essa categoria revela que, em alguns casos, a troca de informações pode ficar mais restrita a um pequeno número de companheiros mais próximos, sendo que há também colegas com certa dificuldade de interação social, o que tolhe suas perspectivas para prover e receber conhecimentos.

Em suma, infere-se que ambas as Empresas $Y$ e $Z$ atendem de modo aceitável aos requisitos para uma relação positiva e produtiva dos sujeitos com a informação, descritos por Marchand, Kettinger e Rollins (2001), anteriormente mencionados. Entretanto, apurou-se a necessidade de aperfeiçoamento em ambas as empresas, no que tange à formalização da informação, enfocando a documentação de software. 
Tendo um panorama sobre as culturas das Empresas $Y$ e $Z$ e possíveis aspectos da cultura profissional, pode-se fazer uma caracterização dessas culturas. O modelo de análise de Hofstede, Pedersen e Hofstede (2002) determina cinco fatores relevantes: identidade, a tendência da cultura para o individualismo ou coletivismo; hierarquia, referente à maior ou menor distribuição de poder; gênero, referente à competitividade, controle, agressividade e questões correlatas; veracidade ou nível de aceitação da incerteza; virtude ou orientação para longo/curto prazo.

Nesse intuito, inferem-se algumas características da cultura profissional dos desenvolvedores de software das empresas pesquisadas, seja no aspecto de 'gênero', o que Hofstede, Pedersen e Hofstede (2002) definem metaforicamente como cultura 'masculina': competitiva, que preza a velocidade; favorável à aceitação da incerteza e do risco, visto que o contexto mercadológico e tecnológico muda constantemente; coletivista, visto que a complexidade das atividades e o uso de métodos ágeis tornam imprescindível o trabalho em equipe; relativa inconsistência na elaboração de documentação e perspectiva 'prática e objetiva' sobre esta denotam uma orientação predominantemente para o curto prazo. Quanto à hierarquia, é evidente a existência de considerável liberdade no aspecto comunicacional, embora em uma das empresas haja uma possível verticalização na estrutura de poder.

Em um quadro de características culturais predominantes, cada empresa tem suas peculiaridades. No aspecto de gênero, a Empresa Z parece mais afeita ao controle e à disciplina, enquanto a Empresa $Y$ se mostra mais livre e aberta. Embora a cultura da Empresa $Z$ tenha dado evidências de ser predominantemente coletivista, apuraram-se evidências de alguns entraves na socialização.

De modo geral, verifica-se que os elementos observados na literatura referentes à relação dos desenvolvedores de software com a informação (Seção 2.2) foram identificados no estudo realizado, assim como também se identificou a influência dos fatores culturais já discutidos (Seção 2.1). Contudo, outros aspectos coletados da literatura, como questões de qualidade da documentação de software e fatores motivacionais do compartilhamento de informação e conhecimento, não foram tratados explicitamente, por razões de concisão. A qualidade da documentação pode ser inferida pela sua relativa incompletude e/ou dificuldade de interpretação evidenciadas. Souza e Moraes (2008) ressaltam que criar um ambiente organizacional amistoso, que possibilite a interação interpessoal, bem como prover a satisfação das necessidades físicas, psicológicas e sociais dos colaboradores, contribui como fator motivacional para aumentar os fluxos de informação e conhecimento nas empresas de software, o que se observou com mais intensidade na empresa Y. 


\section{Considerações finais}

Por meio de uma perspectiva inspirada na fenomenologia e na hermenêutica de Paul Ricoeur, buscou-se analisar as práticas informacionais dos profissionais de desenvolvimento de software. Utilizada com uma função heurística, essa perspectiva fenomenológica fez emergir valores coletivos internalizados, contidos nos discursos dos gestores e colaboradores das empresas de software. Apurou-se, ainda, a influência das culturas profissional, organizacional e informacional sobre a relação dos desenvolvedores de software com a informação e o conhecimento.

Com respeito ao problema de pesquisa apresentado - "quais são as características da cultura profissional dos desenvolvedores de software que determinam sua relação com a informação?" -, são elencados: sigilo e ética informacionais; acessibilidade para socialização de informação e conhecimentos; rastreabilidade da informação; visão positiva sobre os erros; relevância da Internet como fonte de informação; elaboração de documentação sucinta; carências na documentação externa; carências na documentação interna; rotina atarefada e stress moderado. Esses fatores culturais, consequências do contexto mercadológico, da educação profissional e dos valores socializados nas comunidades profissionais, são passíveis de generalização analítica, como discorrido anteriormente (Seção 3), visto que se confirmaram pela literatura científica precedente, bem como se mostraram replicáveis em ambas as empresas pesquisadas.

Referente à questão "de que maneira as culturas organizacional e informacional interagem com a cultura profissional?", constatou-se que os fatores da cultura profissional concernentes à relação dos desenvolvedores de software com a informação e o conhecimento são vivenciados de maneira particular em cada empresa, acrescentando-se a eles outros fatores, peculiares às respectivas culturas organizacionais. Como já discutido (Seção 4), a cultura profissional dos desenvolvedores de software pode ser enquadrada como competitiva e acelerada, coletivista e orientada para o presente, para curto prazo, dentre outras características, implicando num enfoque na socialização informal de informações e conhecimentos e dificuldades para registrá-los. As culturas das empresas pesquisadas diferem, principalmente, no seguinte: enquanto a $Y$ incentiva mais o contato pessoal e a socialização, a $Z$ dá maior ênfase ao trabalho padronizado e metódico, refletindo uma documentação de requisitos relativamente bem estruturada, apesar de evidências de possíveis lacunas em outros tipos de documentação.

Referente ao problema de pesquisa - "quais os aspectos das práticas informacionais dos referidos profissionais são adequados à execução eficaz do trabalho e quais problemas podem ser identificados?" -, apontam-se como aspectos positivos: o sigilo e ética informacionais; 
acessibilidade para socialização de informação e conhecimentos; rastreabilidade da informação; visão positiva sobre os erros; elaboração de documentação sucinta. Como pontos a melhorar, destacam-se as lacunas na documentação e o relativo stress, que denota restrições de tempo para o compartilhamento e registro de informações.

Portanto, é relevante que haja incentivo para a elaboração e manutenção de uma documentação de projetos consistente, bem como conscientização sobre sua importância, e que os gestores estejam atentos à sobrecarga de trabalho, permitindo que haja tempo hábil para o compartilhamento de informação e conhecimentos. Visto a ênfase dada ao trabalho em equipe, é pertinente criar espaços e políticas que propiciem a interação pessoal e socialização de conhecimentos. Sendo a Internet o principal canal dos sujeitos pesquisados para obtenção de informação, é necessário que eles sejam instruídos na identificação e uso de fontes confiáveis e seguras. Assim, argumenta-se que as discussões apresentadas podem ser úteis para explicar alguns fenômenos desse âmbito profissional e servir como ponto de partida para estudos mais aprofundados.

Como limitações do trabalho, destaca-se que os resultados obtidos são referentes ao setor de desenvolvimento de softwares empresariais, no qual as metodologias ágeis são padrão consolidado há cerca de duas décadas, como já exposto anteriormente (Seção 2.2). Contudo, em outros setores, que empregam modelos de trabalho distintos, como o desenvolvimento de softwares críticos, dos quais se exige alto grau de confiabilidade, requerendo uma ênfase maior na documentação e desenvolvimento meticuloso, possivelmente os resultados seriam distintos.

Por fim, conclui-se que o trabalho evidenciou a estreita relação entre as culturas profissional, organizacional, informacional e as práticas laborais, que determinam fortemente os valores dessas culturas. As práticas informacionais se revelam na confluência dessas culturas, agindo sobre os usos, atitudes e percepções socialmente partilhados diante da informação. Essas práticas informacionais, construídas na experiência empírica do trabalho, necessitam ser refletidas à luz dos aportes teóricos da $\mathrm{Cl}$, ampliando seu entendimento, corrigindo possíveis concepções equivocadas dos praticantes, aprimorando aspectos positivos e contribuindo para o atingimento dos objetivos organizacionais.

\section{Referências}

ABRAMOV, R. N. The professional culture of Russian engineering and technical specialists. Sociological Research, v. 56, n. 6, p. 418-430, 2017. Disponível em: https://doi.org/10.1080/10610154.2017.1407598 Acesso em: 25 jan. 2019.

AHMED, T.; SRIVASTAVA, A. Understanding and evaluating the behavior of technical users. A study of developer interaction at Stack Overflow. Human-Centric Computing and Information 
Sciences, Taiwan, v. 7, n. 8, p. 1-18, 2017. Disponível em: https://doi.org/10.1186/s13673-0170091-8 Acesso em: 25 jan. 2019.

ALMEIDA JÚNIOR, O. F. Mediação da informação: um conceito atualizado. In: BORTOLIN, S.; SANTOS NETO, J. A.; SILVA, R. S. (Org.). Mediação oral da informação e da leitura. Londrina: ABECIN, 2015. p. 9- 32.

AMERICAN PSYCHOLOGICAL ASSOCIATION. APA Dictionary of Psychology. [S. I.]: APA, 2018. Disponível em: https://dictionary.apa.org/motivation Acesso em: 14 jun. 2019.

ARAÚJO, C. A. A. O que são "práticas informacionais"? Informação em Pauta, Fortaleza, v. 2, p. 217- 236, out. 2017. Disponível em: http://dx.doi.org/10.32810/2525-3468.ip.v2i0.2017.20655 Acesso em: 25 jan. 2019.

ASGARI, F.; JAFARI, M.; RAMAZANI, A. Investigating the relationship between organizational factors of stress and delay of software projects in a large knowledge based company. Independent Journal of Management \& Production, v. 8, n.1, p. 15-33, Jan./Mar. 2017. Disponível em: https://doi.org/10.14807/ijmp.v8i1.487 Acesso em: 25 jan. 2019.

ASSOCIAÇÃO BRASILEIRA DAS EMPRESAS DE SOFTWARE. Mercado Brasileiro de Software: panorama e tendências, 2019. São Paulo: ABES, 2019. Disponível em: http://central.abessoftware.com.br/Content/UploadedFiles/Arquivos/Dados\%202011/ABES-

EstudoMercadoBrasileirodeSoftware2019.pdf Acesso em: 01 fev. 2020.

ASSOCIAÇÃO DE EMPRESAS DE SERVIÇOS DE TECNOLOGIA DA INFORMAÇÃO. Quem somos. Marília: 2020. Disponível em: http://asserti.org/pages/asserti.aspx Acesso em: 1 fev. 2020.

ASSOCIAÇÃO PARA PROMOÇÃO DA EXCELÊNCIA DO SOFTWARE BRASILEIRO. Apoio, execução e fomento às políticas públicas para o setor de TIC. Brasília: SOFTEX, 2018. Disponível em: https://softex.br/booksoftex/ Acesso em: 1 fev. 2020.

BALLE, A. R. et al. How do knowledge cycles happen in software development methodologies? Industrial and Commercial Training, v. 50, n. 7, p. 380- 392, 2018. Acesso em: 24 jan. 2019. Disponível em: https://doi.org/10.1108/ICT-04-2018-0037

BARDIN, L. Análise de Conteúdo. 3. ed. Lisboa: Edições 70, 2004.

BIEMEL, W.; SPIEGELBERG, H. Phenomenology. In: Britannica Academic. [S.I]: Encyclopædia Britannica, 2008. Disponível em: https://academic.eb.com/levels/collegiate/article/phenomenology/108681 Acesso em: 18 jun. 2019.

BLANCO-ILARI, J. I. La fenomenología hermenéutica de la persona según Paul Ricoeur. Revista de Filosofía y Teoría Política, v. 36, p. 29-52, 2005. Disponível em: http://sedici.unlp.edu.ar/bitstream/handle/10915/12548/Documento completo.pdf?sequenc e=1\&isAllowed=y Acesso em: 25 jan. 2019.

BRAIDA, C. R. Apresentação. In: SCHLEIERMACHER, F. Hermenêutica: arte e técnica da interpretação. Petropolis: Vozes, 1999. p. 7-22. 
BUDD, J. M. Phenomenology and information studies. Journal of Documentation, v. 61, n.1, p. 44-59, 2005. Disponível em: https://doi.org/10.1108/00220410510578005 Acesso em: 25 jan. 2019.

CALEFATO, F.; LANUBILE, F.; NOVIELLI, N. How to ask for technical help? Evidence-based guidelines for writing questions on Stack Overflow. Information and Software Technology, v. 94, p. 186-207, 2018. Disponível em: http://dx.doi.org/10.1016/i.infsof.2017.10.009 Acesso em: 25 jan. 2019.

CAPURRO, R. Epistemología y ciencia de la información. Enl@ce, Maracaibo, v. 4, n. 1, p. 11-29, jan./abr. 2007. Disponível em: http://www.redalyc.org/articulo.oa?id=82340102 Acesso em: 29 jan. 2018.

DAVENPORT, T. H.; PRUSAK, L. Ecologia da informação: porque só a tecnologia não basta para o sucesso na era da informação. São Paulo: Futura, 1998.

DUARTE, A. B. S.; ARAÚJO, C. A. A.; PAULA, C. P. A. Práticas informacionais: desafios teóricos e empíricos de pesquisa. Informação em Pauta, Fortaleza, v. 2, p. 111-135, out. 2017. Disponível em: http://dx.doi.org/10.32810/2525-3468.ip.v2i0.2017.20650 Acesso em: 25 jan. 2019.

GARÇA. PREFEITURA MUNICIPAL. Secretaria Municipal de Informação e Comunicação. 0 município. Garça: 2018. Disponível em: https://www.garca.sp.gov.br/cidade Acesso em: 7 abr. 2018.

GRIFFIN, R. W.; MOORHEAD, G. Fundamentos do comportamento organizacional. São Paulo: Ática, 2006.

HANSEN, P.; WIDÉN, G. The embeddedness of collaborative information seeking in information culture. Journal of Information Science, v. 43, n. 4, p. 554-566, 2016. Disponível em: https://doi.org/10.1177/0165551516651544 Acesso em: 25 jan. 2019.

HOLLIFIELD, A. C.; KOSICKI, G. M.; BECKER, L. B. Organizational vs. professional culture in the newsroom: television news directors' and newspaper editors' hiring decisions. Journal of Broadcasting \& Electronic Media, v. 45, n.1, p. 92-117, 2001. Disponível em: https://doi.org/10.1207/s15506878jobem4501 7 Acesso em: 25 jan. 2019.

HOFSTEDE, G. J.; PEDERSEN, P. B.; HOFSTEDE, G. Exploring culture: exercises, stories and synthetic cultures. Boston: Intercultural Press, 2002.

HUFF, R. Organizational culture. In: Britannica Academic. [S.I.]: Encyclopaedia Britannica, 2014. Disponível em: https://academic-ebbritannica.ez87.periodicos.capes.gov.br/levels/collegiate/article/organizationalculture/600993 Acesso em: 14 jun. 2019.

KARAHANNA, E.; EVARISTO, J. R.; STRITE, M. Levels of culture and individual behavior: an integrative perspective. Journal of Global Information Management, v. 13, n. 2, p. 1-20, 2005. Disponível em: https://www.researchgate.net/publication/269557801 Levels of Culture and Individual Be havior An Integrative Perspective Acesso em: 16 maio 2020. 
KORIAT, N.; GELBARD, R. Knowledge sharing motivation among external and internal IT workers. Journal of Information \& Knowledge Management, v. 17, n. 3, p. 1-24, 2018. Disponível em: https://doi.org/10.1142/S0219649218500260 Acesso em: 20 jan. 2019.

MARCHAND, D. A.; KETTINGER, W. J.; ROLLINS, J. D. Information orientation: The link to business performance. Oxford: Oxford University Press, 2001.

MANTZAVINOS, C., Hermeneutics. In: The Stanford Encyclopedia of Philosophy. Stanford (CA), Stanford University, 2016. Disponível em: https://plato.stanford.edu/archives/win2016/entries/hermeneutics/ Acesso em: 18 jun. 2019.

MORAES, L. B.; BARBOSA, R. R. Cultura informacional: uma proposta de modelo com foco organizacional. Informação \& Sociedade: Estudos, João Pessoa, v. 25, n. 3, p. 131- 146, set./dez. $2015 . \quad$ Disponível em: http://www.periodicos.ufpb.br/ojs/index.php/ies/article/view/21904/14533 Acesso em: 25 jan. 2019.

PAUL RICOEUR. In: Britannica Academic. [S.I.]: Encyclopædia Britannica, 2005. Disponível em: academic.eb.com/levels/collegiate/article/Paul-Ricoeur/63622 Acesso em: 17 jun. 2019.

PETERS, J. F.; PEDRYCZ, W. Engenharia de software. Rio de Janeiro: Campus, 2001.

PFLEEGER, S. L. Engenharia de software: teoria e prática. 2. ed. São Paulo: Prentice Hall, 2004.

RENDÓN-ROJAS, M. A.; HERNÁNDEZ-SALAZAR, P. Sense-making: ¿metateoría, metodología o heurística? Investigación Bibliotecológica, v. 24, n. 50, p. 61- 81, 2010. Disponível em: http://www.scielo.org.mx/pdf/ib/v24n50/v24n50a5.pdf Acesso em: 25 jan. 2019.

SARACEVIC, T. Information Science. Journal of the American Society for Information Science, $v$. 50, n.12, p. 1051-1063, out. 1999. Disponível em: http://onlinelibrary.wiley.com/doi/10.1002/(SICI)1097-4571(1999)50:12\%3C1051::AIDASI2\%3E3.0.CO;2-Z/epdf Acesso em: 17 nov. 2017.

SCHEIN, E. H. Guia de sobrevivência da cultura corporativa. 2. ed. Rio de Janeiro: José Olímpio, 2007.

SHROPSHIRE, J.; KADLEC, C. I'm leaving it field: The impact of stress, job insecurity, and burnout on it professionals. International Journal of Information and Communication Technology Research, v. 2, n. 1, p. 6-16, jan. 2012. Disponível em: https://pdfs.semanticscholar.org/884d/a2e769ad032dd5fe35b2aa08212336dba802.pdf

Acesso em: 25 jan. 2019.

SIEGRIST, Hannes. Professions and Professionalization, History of. In: International Encyclopedia of the Social \& Behavioral Sciences. 2. ed. [S. I.]: Elsevier, 2015. v. 19. Disponível em: http://dx.doi.org/10.1016/B978-0-08-097086-8.62020-2 Acesso em: 30 out. 2019.

SOMMERVILLE, I. Engenharia de software. 8. ed. São Paulo: Pearson Education, 2007.

SOUZA, L. P. P. O comportamento informacional dos desenvolvedores de software no contexto da cultura organizacional enfatizando o compartilhamento e reuso de informações. 2019. 287 f. Dissertação (Mestrado em Ciência da Informação) - Faculdade de Filosofia e Ciências, Universidade Estadual Paulista, Marília, 2019. 287 p. 
SOUZA, L. P. P.; MORAES, C. R. B. Influência do clima organizacional para o compartilhamento de conhecimento tácito no desenvolvimento de software. In: Encontro sobre Ciência, Tecnologia e Gestão da Informação, 8., 2018, Recife. Anais... Recife: Universidade Federal de Pernambuco,
2018.
p.
$132-$
144.
Disponível
em:

https://drive.google.com/file/d/1WQTT6UhgGXQM5eNxleLljuCTfElwtzG7/view Acesso em: 31 mar. 2019.

STENIUS, M. et al. Why share expertise? A closer look at the quality of motivation to share or withhold knowledge. Journal of Knowledge management, v. 20, n. 2, p. 181-198, 2016. Disponível em: https://doi.org/10.1108/JKM-03-2015-0124 Acesso em: 25 jan. 2019.

TAKEUCHI, H.; NONAKA, I. Gestão do conhecimento. Porto Alegre: Bookman, 2008.

TERRA, M. G. et al. Fenomenologia-hermenêutica de Paul Ricoeur como referencial metodológico numa pesquisa de ensino em enfermagem. Acta Paulista de Enfermagem, v. 22, n. 1, p. 93-99, 2009. Disponível em: http://dx.doi.org/10.1590/S0103-21002009000100016 Acesso em: 25 jan. 2019.

TERRETT, A. Knowledge Management and the Law Firm. Journal of Knowledge Management; $\mathrm{v}$. 2, n. 1, p. 67-76, 1998. Disponível em: https://doi.org/10.1108/EUM0000000004608 Acesso em: 28 jul. 2019.

TERTO, A. L. de V.; Duarte, A. B. S. A prática informacional dos usuários de um sistema de informação a partir de uma perspectiva compreensiva. Biblios, n. 54, p. 51-70, 2014. Disponível em: https://doi.org/10.5195/biblios.2014.140 Acesso em: 25 jan. 2019.

UNIVERSIDADE ESTADUAL PAULISTA. Tipos de revisão de literatura. Botucatu: UNESP, 2015. Disponivel em: https://www.fca.unesp.br/Home/Biblioteca/tipos-de-evisao-de-literatura Acesso em: 16 maio 2020.

VALENTIM, M. L. P. Ambientes e fluxos de informação em contextos empresariais: o caso do setor cárnico de Salamanca/Espanha. Brazilian Journal of Information Science, v. 7, n. Especial, p. 299-323, 2013. Disponível em: http://www2.marilia.unesp.br/revistas/index.php/bjis/article/view/3130/2475 Acesso em: 18 maio 2020.

VALENTIM, M. L. P. Comportamento informacional por empresas competitivas. In: CASARIN, H. C. S. (Org.). Estudos de usuário da informação. Brasília: Thesaurus, 2014. p. 165-182.

WOIDA, L. M.; VALENTIM, M. L. P. Cultura organizacional/cultura informacional: a base do processo de inteligência competitiva organizacional. In: VALENTIM, M. L. P. (Org.). Informação, conhecimento e inteligência organizacional. Marília: FUNDEPE Editora, 2006.

YIN, R. K. Case study research: design and methods. 4. ed. Thousand Oaks (CA): SAGE, 2009.

ZHI, J. Cost, benefits and quality of software development documentation: A systematic mapping. The Journal of Systems and Software, v. 99, p. 175-198, 2015. Disponível em: http://dx.doi.org/10.1016/j.jss.2014.09.042 Acesso em: 25 jan. 2019. 
